\title{
Inspecting the Mechanism: An Analytical Approach to the Stochastic Growth Model
}

\section{Citation}

Campbell, John Y. 1994. Inspecting the Mechanism: An Analytical Approach to the Stochastic Growth Model. Journal of Monetary Economics 33, no. 3: 463-506.

\section{Published Version}

http://dx.doi.org/10.1016/0304-3932(94)90040-X

\section{Permanent link}

http://nrs.harvard.edu/urn-3:HUL.InstRepos:3196342

\section{Terms of Use}

This article was downloaded from Harvard University's DASH repository, and is made available under the terms and conditions applicable to Other Posted Material, as set forth at http:// nrs.harvard.edu/urn-3:HUL.InstRepos:dash.current.terms-of-use\#LAA

\section{Share Your Story}

The Harvard community has made this article openly available.

Please share how this access benefits you. Submit a story.

Accessibility 
NBER WORKING PAPER SERIES

\author{
INSPECTING THE MECHANISM: \\ AN ANALYTICAL APPROACH TO THE \\ STOCHASTIC GROWTH MODEL
}

John Y. Campbell

Working Paper No. 4188

\author{
NATIONAL BUREAU OF ECONOMIC RESEARCH \\ 1050 Massachusetts Avenue \\ Cambridge, MA 02138 \\ October 1992
}

I am grateful to Ben Bernanke, Gregory Chow, Angus Deaton, and participants at the Princeton Macro Lunch for helpful comments, to the National Science Foundation and the Sloan Foundation for financial support, and to Donald Dale for research assistance. This paper is part of NBER's research program in Economic Fluctuations. Any opinions expressed are those of the author and not those of the National Bureau of Economic Research. 
NBER Working Paper \#4188

October 1992

\title{
INSPECTING THE MECHANISM: \\ AN ANALYTICAL APPROACH TO THE \\ STOCHASTIC GROWTH MODEL
}

\begin{abstract}
This paper argues that a clear understanding of the stochastic growth model can best be achieved by working out an approximate analytical solution. The proposed solution method replaces the true budget constraints and Euler equations of economic agents with loglinear approximations. The model then becomes a system of loglinear expectational difference equations, which can be solved by the method of undetermined coefficients. The paper uses this technique to study shocks to technology and govemment consumption. It emphasizes that the persistence of shocks is an important determinant of their macroeconomic effects.
\end{abstract}

John Y. Campbell

Woodrow Wilson School

Robertson Hall

Princeton University

Princeton, NJ 08544-1013

and NBER 


\section{Introduction}

During the last ten years, the stochastic growtl model has become a workhorse for macroeconomic analysis. Perhaps the most forceful claims for the model have been made by Prescott (1986), who describes it as "a paradigm for macro analysis analogous to the supply and demand construct of price theory". Prescott also refers to the predictions of the model as those of "standard economic theory". In Prescott's view the shocks to the economy are random variations in the rate of technical progress, but the usefulness of the stochastic growth model does not depend on this view of the sources of business cycles. Other authors have subjected the model to other types of shocks, for example government consumption (Aiyagari, Christiano, and Eichenbaum 1990, Baxter and King 1990a, Christiano and Eichenbaum 1991a), distorting taxation (Baxter and King 1990a, Greenwood and Huffman 1991, McGrattan 1991), and nominal shocks in the presence of sticky nominal wages and prices (King 1991) or liquidity effects (Christiano and Eichenbaum 1991b). The stochastic growtl model enables one to track the dynamic effects of any shock; in this sense it is indeed a paradigm for macroeconomics.

Despite the wide popularity of the stochastic growth moclel, there is no generally agreed procedure for solving it. The difficulty is the fundimental nonlinearity that arises from the interaction between multiplicative elements such as Cobb-Douglas production with labor and capital, and additive elements such as capital accumulation and depreciation. This nonlinearity disappears only in the unrealistic special case where capital depreciates fully in a single period and agents have log utility (Long and Plosser 1983, McCallun 1989). In this case the model becomes loglinear and can be solved analytically. In all other cases, some approximate solution method is required.

In a seminal contribution, Kydland and Prescott (1982) proposed taking a linearquadratic approximation to the true model around a steady-state growth path. Hansen and Sargent (1991) have extended this approach. Christiano (1988) and King, Plosser, and Rebelo (1987) have used a loglinear-quadratic approximation instead. This has at least two advantages: First, it delivers the correct solution in the special case that can be solved exactly, and second, it gives a simpler relation between the parameters of the underlying model and the parameters that appear in the approximate solution. Many other methods are also available, and have recently been reviewed and compared by 
Taylor and Uhlig (1990). Most of these methods are heavily numerical rather than analytical. While computational costs are no longer an important objection to numerical methods, the methods are often mysterious to the non-initiate and seem to bear little relation to familiar techniques for solving linear rational expectations models. A typical paper in the real business cycle literature states the model, then moves directly to a discussion of the properties of the solution without giving the reader the opportunity to understand the mechanism giving rise to these properties. ${ }^{1}$

In this paper I propose a simple, analytical approach to the stochastic growth model. I take the model's Euler equations and budget constraints and loglinearize them in the manner of Campbell and Shiller (1988) and Campbell (1990). This transforms the model into a system of expectational difference equations in the capital stock and the exogenous variables driving the economy (here taken to be technology or government spending). I solve this system analytically using the method of undetermined coefficients.

There are important similarities, but also important differences, between this approach and the work of Christiano (1988) and King, Plosser, and Rebelo (1987). Cliristiano (1988) first substitutes all budget constraints into the objective function to set the model up as a calculus of variations problem. He then takes a second-order Taylor approximation in logs of the variables. Despite Christiano's use of a higher-order approximation, in a homoskedastic setting his method yields the same solution as the one obtained in this paper. The reason is that only expectations of second-order terms appear in Christiano's solution, and these expectations are constant if the model is homoskedastic. It follows that the evidence of Taylor and Uhlig (1900) and Christiano (1989) on numerical accuracy applies to the method of this paper as well. King; Plosser, and Rebelo (1987) write the model's first-order conditions using the Lagrange multiplier for the budget constraint as a state variable, and then loglinearize to obtain a systern of expectational difference equations in the capital stock and the Lagrange multiplier. This is similar to the approach here, except that I use the capital stock and the exogenous driving variables as the state variables. This enables me to dorive more directly the responses of endogenous variables to shocks in exogenous variables.

Perhaps the most important difference between this paper and previous work is that I solve the systern of loglinear difference equations analytically in order to make the

\footnotetext{
1 The problem is also illustrated by Chapter 7 of Blanchard and Fischer (1989). Quite appropriately, this textbook confines itself to small macro models that can be solved analytically; lacking an appropriate solution method, Chapter 7 fails to convey the richness of the stochastic growth model or the real business cycle literature.
} 
mechanics of the solution as transparent as possible. King, Plosser, and Rebelo (1987) instead solve the system using a general numerical method which can be more easily generalized to models with multiple state variables, but which obscures the simplicity of the basic stoclastic growth model.

To illustrate the usefulness of the approach, this paper studies a number of issues in real business cycle analysis. Section 2 studies the effect of technology shocks in a model with fixed labor supply, showing how the insights of the literature on the permanent income hypothesis can be embedded in the stochastic growth nodel. Section 3 studies two alternative models of variable labor supply. In both sections the analytical solution method clarifies how the properties of the model depend on the parameters of the utility function and the persistence of technology shocks. As an illustration of the importance of persistence, the paper studies a slowdown in productivity growth of the type that seems to have occurred in the mid-1970's. Section 4 introduces shocks to government consumption, again emphasizing the importance of persistence. Section 5 concludes. 


\section{A Model with Fixed Labor Supply}

The first equation of the model is a standard Cobb-Douglas production function. Using the notation $Y_{t}$ for output, $A_{t}$ for technology, and $K_{t}$ for capital, and normalizing labor input $N_{t}=1$, the production function is

$$
Y_{t}=\left(A_{t} N_{t}\right)^{\alpha} K_{t}^{1-\alpha}=A_{t}^{\alpha} K_{t}^{1-\alpha}
$$

The second equation of the model describes the capital accumulation process:

$$
K_{t+1}=(1-\delta) K_{t}+Y_{t}-C_{t},
$$

where $\delta$ is the depreciation rate. Finally, the objective function of the representative agent is:

$$
\operatorname{Max} E_{t} \sum_{i=0}^{\infty} \beta^{i} U\left(C_{t+i}\right)=E_{t} \sum_{i=0}^{\infty} \beta^{i} \frac{C_{t+i}^{1-\gamma}}{1-\gamma} .
$$

This time-separable power utility function with coefficient of relative risk aversion $\gamma$ becomes the $\log$ utility function when $\gamma=1$. I define the elasticity of intertemporal substitution $\sigma \equiv 1 / \gamma$.

I also define a variable $R_{t+1}$, equal to the gross marginal product of capital:

$$
R_{i+1} \equiv(1-\alpha)\left(\frac{A_{t+1}}{K_{t+1}}\right)^{\alpha}+(1-\delta)
$$

The first-order condition for optimal choice, given the objective function (2.3) and the constraints (2.1) and (2.2), can then be written in the simple form

$$
C_{t}^{-\gamma}=\beta E_{t}\left\{C_{t+1}^{-\gamma} R_{t+1}\right\}
$$




\section{Steady state growth}

I now look for a steady state or balanced growth path of this model, in which technology, capital, output, and consumption all grow at a constant common rate. I use the notation $G$ for this growth rate: $G \equiv A_{t+1} / A_{t}$. In steady state the gross marginal product of capital $R_{t+1}$ becomes a constant $R$, while the first-order condition (2.5) becomes

$$
G^{\gamma}=\beta R,
$$

or in logs (denoted by lower-case letters),

$$
g=\frac{\log (\beta)+r}{\gamma}=\sigma \log (\beta)+\sigma r .
$$

This is the familiar condition relating the equilibrium growth rate of consumption to the intertemporal elasticity of substitution times the real interest rate in a model with power utility.

The definition of $R(2.4)$ and the first-order condition (2.6) imply that the technologycapital ratio is given by

$$
\frac{A_{t}}{K_{t}}=\left[\frac{G^{\gamma} / \beta-(1-\delta)}{1-\alpha}\right]^{\frac{1}{\alpha}} \approx\left[\frac{r+\delta}{1-\alpha}\right]^{\frac{1}{\alpha}} \text {. }
$$

The first equality in (2.8) shows that a higher rate of technology growth leads to a lower capital stock for a given level of technology. The reason is that in steady state, faster technology growth must be accompanied by faster consumption growth. Agents will accept a steeper consumption path only if the marginal product of capital is higher, which requires a lower capital stock. The second approximate equality in (2.8) comes from setting $G^{\gamma} / \beta=R \approx 1+r$.

More generally, one can solve for various ratios of variables that will be constant along a steady-state growth path. I express these ratios in terms of four underlying parameters: $g$, the $\log$ technology growth rate; $r$, the log marginal product of capital 
or $\log$ real interest rate; $\alpha$, the exponent on labor and technology in the production function, or equivalently labor's share of output; and $\delta$, the rate of capital depreciation. For purposes of "calibration" in a quarterly model, benchmark values for these parameters might be $g=0.005$ ( $2 \%$ at an annual rate), $r=0.015$ (6\% at an annual rate), $\alpha=0.667$, and $\delta=0.025$ (10\% at an annual rate). ${ }^{2}$ Note that the rate of time preference $\beta$ and the coefficient of risk aversion $\gamma$ need not be specified, although (2.7) defines pairs of values for $\beta$ and $\gamma$ that are consistent with the assumed values of $g$ and $r$.

Using the production function (2.1) and the formula for the technology-capital ratio (2.8), we have that the output-capital ratio is

$$
\frac{Y_{t}}{K_{t}}=\left(\frac{A_{t}}{K_{t}}\right)^{\alpha} \approx \frac{r+\delta}{1-\alpha}
$$

Similar reasoning shows that the consumption-output ratio is

$$
\frac{C_{t}}{Y_{t}}=\frac{C_{t} / K_{t}}{Y_{t} / K_{t}} \approx 1-\frac{(1-\alpha)(g+\delta)}{r+\delta}
$$

At the benchmark parameter values given above, the output-capital ratio $Y_{t} / I_{t}=0.118$ (0.472 at an annual rate), and the consumption-output ratio $C_{t} / Y_{t}=0.745$. These are fairly reasonable values. ${ }^{3}$

\section{A loglinear model of fluctuations}

Outside steady state, the real business cycle model is a system of nonlinear equations in the logs of technology, capital, output, and consumption. Nonlinearities are caused by incomplete capital depreciation $(\delta<1$ in (2.2) and (2.4)), and by timevariation in the consumption-output ratio. Thus exact analytical solution of the model is only possible in the unrealistic special case where capital depreciates fully in one period, and where agents have $\log$ utility so the consumption-output ratio is constant (Long and Plosser 1983, McCallum 1989). The strategy of this section is instead to seek an approximate analytical solution by transforming the model into a system of

\footnotetext{
${ }^{2}$ The most controversial of these benchmark parameler values is probably the $6 \%$ real interest rate. This is intended to represent the rate of return to capital, and not the rate of return to a nominally rishless short-term asset.

${ }^{3}$ Simon (1990) briefly surveys alternative estimates of these ratios.
} 
approximate loglinear difference equations. For simplicity, all constant terms will be suppressed in the approximate model; the variables in the system can be thought of as zero-mean deviations from the steady-state growth path.

The Cobb-Douglas production function (2.1) needs no approximation; it can be written in loglinear form as

$$
y_{t}=\alpha a_{t}+(1-\alpha) k_{t}
$$

where as always lower-case letters are used for log variables.

The capital accumulation equation (2.2) is unfortunately not loglinear. Dividing by $K_{t}$ and taking $\log s,(2.2)$ becomes

$$
\log \left[\exp \left(\Delta k_{t+1}\right)-(1-\delta)\right]=y_{t}-k_{t}+\log \left[1-\exp \left(c_{t}-y_{t}\right)\right]
$$

The strategy proposed here is to take first-order Taylor approximations of the functions on the left and right hand sides of (2.12) around their steady state values, and then to substitute out $y_{t}$ using the log production function (2.11). Calculations summarized in Appendix A yield the following loglinear approximate accumulation equation:

$$
k_{t+1} \approx \lambda_{1} k_{t}+\lambda_{2} a_{t}+\left(1-\lambda_{1}-\lambda_{2}\right) c_{t}
$$

where

$$
\lambda_{1} \equiv \frac{1+r}{1+g}, \quad \lambda_{2} \equiv \frac{\alpha(r+\delta)}{(1-\alpha)(r+g)} .
$$

At the benchmark parameter values discussed above, $\lambda_{1}=1.01, \lambda_{2}=0.08$, and $1-\lambda_{1}-\lambda_{2}=-0.09$.

I now turn to the general first-order condition (2.5). If the variables on the right hand side of (2.5) are jointly lognormal and homoskedastic, then one can rewrite the 
frrst-order condition in $\log$ form as $E_{t} \Delta c_{t+1}=\sigma E_{t} r_{t+1}$, where $r_{t+1} \equiv \log \left(R_{t+1}\right){ }^{4}$ From the definition of the marginal product of capital $R_{t+1}$ in equation (2.4), the log marginal product $r_{l+1}$ is a nonlinear function of the log technology-capital ratio. The loglinear approximation of this function (calculated in Appendix A) is

$$
r_{t+1} \approx \lambda_{3}\left(a_{t+1}-k_{t+1}\right)
$$

where

$$
\lambda_{3} \equiv \frac{\alpha(r+\delta)}{1+r}
$$

At the benchmark parameter values discussed above, $\lambda_{3}=0.03$. Changes in technology have only small proportional effects on the marginal product of capital because capita! depreciates only slowly, so most of the marginal product is undepreciated capital rather than output from the Cobb-Douglas production function. The log first-order condition becomes

$$
E_{t} \Delta c_{t+1}=\sigma \lambda_{3} E_{t}\left(a_{t+1}-k_{t+1}\right)
$$

To close the model, it only remains to specify a process for the technology shock $a_{i}$. I assume that technology follows a first-order autoregressive or AR(1) process:

$$
a_{t}=\phi a_{t-1}+\epsilon_{t}, \quad-1 \leq \phi \leq 1
$$

The AR(1) coefficient $\phi$ measures the persistence of technology shocks, with the extreme case of $\phi=1$ being a random walk for technology. 5

Equations (2.13), (2.17), and (2.18) form a systen of log-linear expectational difference equations in technology, capital, and consumption. The parameters of these

\footnotetext{
4 This uses the standard formula for the expectation of a lognormal random variable $X_{t+1}: \log \left(E_{t} X_{t+1}\right) \approx E_{t} \log \left(X_{t+1}\right)+$ (1/2) Vart $\log \left(X_{t+1}\right)$. Note that the assumption that the variables in the first-order condition are jointly lognormal and homoskedastic is consistent with a lagnormal homoskedastic productivity shock and the approximations proposed here to solve the model.

${ }^{5}$ Equation (2.18) suppresses a deterministic technology trend growing at rate $g$, since all variables in this section are measured as deviations from the steady-state growth path.
} 
equations include $\lambda_{1}, \lambda_{2}$, and $\lambda_{3}$, which are functions of the underlying growth parameters $r, g, \alpha$, and $\delta$; the intertemporal elasticity of substitution $\sigma$; and the $\operatorname{AR}(1)$ coefficient $\phi$ that measures the persistence of technology shocks. The "calibration" approach to real business cycle analysis takes $\lambda_{1}, \lambda_{2}$, and $\lambda_{3}$ as known, and searches for values of $\sigma$ and $\phi$ (and a variance for the technology innovation) to match the moments of observed macroeconomic time series.

\section{The method of undetermined coefficients}

Equations (2.13), (2.16), and (2.18) can be solved using any of a number of standard methods. Here I use the method of undetermined coefficients. I use the notation $\eta_{y x}$ for the partial elasticity of $y$ with respect to $x$, and guess that $\log$ consumption takes the form

$$
c_{t}=\eta_{c k} k_{t}+\eta_{c a} a_{t}
$$

where $\eta_{c k}$ and $\eta_{c a}$ are unknown but assumed to be constant. I verify this guess by finding values of $\eta_{c k}$ and $\eta_{c a}$ that satisfy the restrictions of the approxinate loglinear model.

The conjectured solution can be written in terms of the capital stock, using (2.13), as

$$
k_{t+1}=\eta_{k k} k_{t}+\eta_{k a} a_{t}
$$

where

$$
\eta_{k k} \equiv \lambda_{1}+\left(1-\lambda_{1}-\lambda_{2}\right) \eta_{c k}, \quad \eta_{k a} \equiv \lambda_{2}+\left(1-\lambda_{1}-\lambda_{2}\right) \eta_{c a}
$$

Also, substituting the conjectured solution into (2.16), I obtain

$$
\begin{aligned}
\eta_{c k} \Delta k_{t+1}+\eta_{c a} E_{t} \Delta a_{t+1} & =\sigma \lambda_{3} E_{t} a_{t+1}-\sigma \lambda_{3} k_{t+1} . \\
-9- &
\end{aligned}
$$


Next I substitute (2.20) and (2.21) into (2.22) and use the fact that $E_{t} a_{t+1}=\phi a_{t}$. The result is an equation in only two state variables, the capital stock and the level of technology:

$\eta_{c k}\left[\lambda_{1}-1+\left(1-\lambda_{1}-\lambda_{2}\right) \eta_{c k}\right] k_{t}+\eta_{c k}\left[\lambda_{2}+\left(1-\lambda_{1}-\lambda_{2}\right) \eta_{c a}\right] a_{t}+\eta_{c a}(\phi-1) a_{t}=$

$\sigma \lambda_{3} \phi a_{t}-\sigma \lambda_{3}\left[\lambda_{1}+\left(1-\lambda_{1}-\lambda_{2}\right) \eta_{c k}\right] k_{t}-\sigma \lambda_{3}\left[\lambda_{2}+\left(1-\lambda_{1}-\lambda_{2}\right) \eta_{c a}\right] a_{t}$.

To solve this equation I first equate coefficients on $k_{t}$ to find $\eta_{c k}$, and then equate coefficients on $a_{t}$ to find $\eta_{c a}$, given $\eta_{c k}$.

Equating coefficients on $k_{t}$ gives the quadratic equation

$$
Q_{2} \eta_{c k}^{2}+Q_{1} \eta_{c k}+Q_{0}=0
$$

where

$$
Q_{2} \equiv 1-\lambda_{1}-\lambda_{2}, \quad Q_{1} \equiv \lambda_{1}-1+\sigma \lambda_{3}\left(1-\lambda_{1}-\lambda_{2}\right), \quad Q_{0} \equiv \sigma \lambda_{3} \lambda_{1} .
$$

The quadratic formula gives two solutions to (2.24), one of which is positive as required by the nature of the problem:

$$
\eta_{c k}=\frac{1}{2 Q_{2}}\left\{-Q_{1}-\sqrt{Q_{1}^{2}-4 Q_{0} Q_{2}}\right\}
$$

Note that $\eta_{c k}$ depends only on $\sigma$ and the $\lambda$ parameters, and is invariant to the persistence of the technology shock as measured by $\phi$. Solution of the model is completed by finding $\eta_{c a}$ as

$$
\begin{gathered}
\eta_{c a}=\frac{-\eta_{c k} \lambda_{2}+\sigma \lambda_{3}\left(\phi-\lambda_{2}\right)}{\phi-1+\left(1-\lambda_{1}-\lambda_{2}\right)\left(\eta_{c k}+\sigma \lambda_{3}\right)} . \\
-10-
\end{gathered}
$$




\section{Time-series implications}

The consumption elasticities $\eta_{c k}$ and $\eta_{c a}$, and the capital elasticities $\eta_{k k}$ and $\eta_{k a}$ derived from them, determine the dynamic behavior of the economy. Using lag operator notation, equation (2.20) gives the capital stock as

$$
k_{t+1}=\frac{\eta_{k a}}{\left(1-\eta_{k k} L\right)} a_{t}
$$

Rewriting equation (2.18) in the same notation, the technology process is

$$
a_{t}=\frac{1}{(1-\phi L)} \epsilon_{t}
$$

These two equations imply that the capital stock follows an $\mathrm{AR}(2)$ process:

$$
k_{t+1}=\frac{\eta_{k a}}{\left(1-\eta_{k k} L\right)(1-\phi L)} \epsilon_{t}
$$

Two points are worth noting about this expression. First, the roots of the capital stock process are $\eta_{k k}$ and $\phi$, which are both real numbers. Thus, unlike the multiplieraccelerator model (Samuelson 1939), the real business cycle model does not produce oscillating impulse responses. Second, the shock to capital at time $t+1$ is the technology shock realized at time $t$. The capital stock is known one period in advance because it is determined by lagged investment and by a nonstochastic depreciation rate.

The stochastic processes for output and consumption are somewhat more com. plicated than the process for capital. The log production function (2.11) determines output as $y_{t}=(1-\alpha) k_{t}+\alpha a_{t}$. In the fixed-labor model the partial elasticities of output with respect to capital and technology are trivially $(1-\alpha)$ and $\alpha$. Substituting (2.29) and (2.30) into this expression, I obtain:

$$
y_{t}=\frac{(1-\alpha) \eta_{k a} L}{\left(1-\eta_{k k} L\right)(1-\phi L)} \epsilon_{t}+\frac{\alpha}{(1-\phi L)} \epsilon_{t}=\frac{\alpha+\left[(1-\alpha) \eta_{k a}-\alpha \eta_{k k}\right] L}{\left(1-\eta_{k k} L\right)(1-\phi L)} \epsilon_{t}
$$


The first equality in (2.31) shows that technological shocks affect output both directly, and indirectly through capital accumulation. The second equality shows that the sum of the two effects is an $\operatorname{ARMA}(2,1)$ process for output.

The solution for consumption is obtained by substituting (2.29) and (2.30) into the expression $c_{t}=\eta_{c k} k_{t}+\eta_{c a} a_{t}$. This too is an $\operatorname{ARMA}(2,1)$ process:

$$
c_{t}=\frac{\eta_{c k} \eta_{k a} L}{\left(1-\eta_{k k} L\right)(1-\phi L)} \epsilon_{t}+\frac{\eta_{c a}}{(1-\phi L)} \epsilon_{t}=\frac{\eta_{c a}+\left(\eta_{c k} \eta_{k a}-\eta_{c a} \eta_{k k}\right) L}{\left(1-\eta_{k k} L\right)(1-\phi L)} \epsilon_{t} .
$$

The capital, output, and consumption processes all have the same autoregressive roots $\eta_{k k}$ and $\phi .^{6}$

\section{Interpretation of the elasticities}

Table 1 reports numerical values of the elasticities $\eta_{c k}$ and $\eta_{c a}$, and $\eta_{k k}$ and $\eta_{k a}$, for the benchmark parameters discussed above and for various choices of the parameters $\sigma$ and $\phi . \sigma$ is set equal to $0,0.2,1,5$, and $\infty$ to cover the whole range of possibilities. These choices for $\sigma$ correspond to values for the discount factor $\beta$ of $\infty, 1.010,0.990$, 0.986 , and 0.985 respectively, since equation (2.7) implies a discount factor greater than one if $\sigma$ is less than $g / r=1 / 3 .^{7}$ The persistence parameter $\phi$ is set equal to $0,0.5$, 0.95 , and 1 , again to cover the whole range of possibilities. Variation in $\phi$ has more important effects on the model when $\phi$ is close to one, which is why both $\phi=0.95$ and $\phi=1$ are included.

Several points are worth noting. First, the coefficient $\eta_{c k}$ does not depend on the persistence of technology shocks $\phi$ but is increasing in the elasticity of intertemporal substitution $\sigma$. To understand this, recall that $\eta_{c k}$ measures the effect on current consumption of an increase in capital with a fixed level of technology. Such an increase has a positive income effect on current consumption that does not depend on the value of $\sigma$. It also lowers the real interest rate, creating a positive substitution effect on current consumption that is stronger the greater the parameter $\sigma$.

Sccond, the coefficient $\eta_{c a}$ is increasing in persistence $\phi$ for low values of $\sigma$, but decreasing for high values of $\sigma$. To understand this, recall that $\eta_{c a}$ measures the effect

\footnotetext{
${ }^{6}$ These results can easily be generalized for more complicated technology processes. For example an AR(p) technology process generates an ARMA $(p+1, p-1)$ for the capital stock and an $\operatorname{ARMA}(p+1, p)$ for output, consumption, and the real interest rate. All these variables have common autoregressive roots.

${ }^{7}$ Kocherlatiota (1988) argues for a small value of $\sigma$ and a time discount factor greater than one.
} 
on current consumption of an increase in technology with a fixed stock of capital. At low values of $\sigma$, substitution effects are weak and the agent responds primarily to income effects. A technology shock has an income effect which is stronger when the shock is more persistent, hence $\eta_{c a}$ increases with $\phi$. At high values of $\sigma$, substitution effects are important. A purely temporary technology shock $(\phi=0)$ does not directly affect the real interest rate; it is like a windfall gain in current output. The agent is deterred from saving this windfall by the increase in the capital stock and reduction in the interest rate that would result, hence $\eta_{c a}$ is large. A persistent technology shock, on the other hand, increases the real interest rate today and in the future. This encourages saving, making $\eta_{c a}$ small or even negative.

\section{Special cases}

It is worth discussing explicitly some special cases of the general model. The case $\phi=1$, in which log technology follows a random walk, is often assumed in the literature (Christiano and Eichenbaum 1991a, King, Plosser, Stock, and Watson 1991, Prescott 1986). In this case the model solution has the property that $\eta_{c k}+\eta_{c a}=1$ and $\eta_{k k}+\eta_{k a}=1$. One can then show that although log technology, capital, output, and consumption follow unit root processes, they are cointegrated because the difference between any two of them is stationary. To see this for log technology and capital, note that (2.32) gives the stochastic process for $\lambda_{3}$ times the log technology-capital ratio. When $\eta_{k k}+\eta_{k a}=1$, the unit autoregressive root cancels with a unit noving average root and we have an $\mathrm{AR}(1)$ for the $\log$ technology-capital ratio with cocfficient $\eta_{k k}$. The real interest rate, of course, follows the same process.

Another interesting special case has $\sigma=\infty$ or equivalently $\gamma=0$, so that the representative agent is risk-neutral. In this case the model solution simplifies considerably because the quadratic coefficient $Q_{2}$ in equation (2.24) becomes negligibly small relative to the other coefficients. (2.24) becomes a linear equation that can be solved to obtain $\eta_{c k}=-\lambda_{1} /\left(1-\lambda_{1}-\lambda_{2}\right)=11.3$, the steady-state value of the capital-consumption ratio. Risk-neutrality fixes the ex ante real interest rate, and hence the level of capital for a given level of technology. With fixed technology any increase in capital is simply consumed, so the derivative of consumption with respect to capital is one and the elasticity $\eta_{c k}$ is the capital-consumption ratio. It follows that an increase in capital today does not increase capital tomorrow, so $\eta_{k k}=0$. Finally, $\eta_{k a}=\phi$ because the capital stock changes proportionally with the level of technology. Capital is an $A R(1)$ process 
with coefficient $\phi$, while output and consumption are $\operatorname{ARMA}(1,1)$ processes.

The opposite extreme case has $\sigma=0$. Here intertemporal substitution is entirely absent from the model. Again the solution simplifies because the intercept $Q_{0}=0$ in the quadratic equation (2.24) for $\eta_{c k}$, which therefore collapses to a linear equation. We have $\eta_{c k}=\left(1-\lambda_{1}\right) /\left(1-\lambda_{1}-\lambda_{2}\right)=0.11$. In this case an increase in capital, with fixed technology, stimulates only as much extra consumption as can be permanently sustained. The derivative of consumption with respect to capital is the annuity value of a unit increase in capital, $-\left(1-\lambda_{1}\right) / \lambda_{1}=(r-g) /(1+r)$, and the elasticity is this derivative times the steady-state capital-consumption ratio. It follows that a unit increase in capital today generates a unit increase in capital tomorrow, so $\eta_{k k}=1$.

It is straightforward to show that when $\sigma=0 \log$ consumption follows a random walk, while $\log$ output and $\log$ capital follow unit root processes cointegrated with $\log$ consumption. This model differs from the $\phi=1$ case in that the stationary linear combination of $\log$ consumption and $\log$ capital is not the $\log$ ratio $c_{t}-k_{t}$, but is instead $c_{t}-\eta_{c k} k_{t}=c_{t}-0.11 k_{t}$. An increase in capital does not lead to a proportional increase in consumption in the long run, because the marginal product of capital is less than the average product. Associated with this, there are some technical difficulties with the $\sigma=0$ model. First, equation (2.7) implies that as $\sigma$ approaches zero, the time discount factor must increase to infinity to maintain a realistic stcady-state interest rate. Second, when $\sigma=0$ and technology is stationary $(\phi<1)$, the log technologycapital ratio is nonstationary. This invalidates the loglinear approximations used to obtain the solution. Thus strictly spealing the discussion above applies only to very siriall but nonzero values of $\sigma$.

Despite these problems, the stochastic growth model with $\sigma=0$ deserves attention because it is a general equilibrium version of the permanent income model of Hall (1978) and Flavin (1981). ${ }^{8}$ In this model temporary technology shocks cause temporary variation in output but not in consumption, so output is more variable than consumption and the consumption-output ratio forecasts changes in output. Fama (1991) advocates a model of this type, but does not provide a formal analysis. Hall (1988) and Campbell and Mankiw (1989) demonstrate the empirical relevance of the model with small $\sigma$ by showing that predictable movements in real interest rates have been only weakly

\footnotetext{
${ }^{8}$ Christiano, Eichentaum, and Marshall (1991) present an alternative general equilibrium permanent income model in which utility is quadratic and production is Leontief in labor and capital. The model developed here uses more standard assumptions.
} 
associated with predictable consumption growth in postwar U.S. data. ${ }^{9}$

The $\sigma=0$ case also plays an interesting role in welfare analysis of the model. The maximized welfare of the representative agent can be written as a loglinear function of capital and technology by approximating Bellman's equation. I write the maximized objective function defined in $(2.3)$ as $V_{t}^{1-\gamma} /(1-\gamma)$, so that $V_{t}$ has the same units as consumption. The loglinear approximation of Bellman's equation (derived in Appendix A) is then

$$
\left(1-\lambda_{1}\right)\left(c_{t}-v_{t}\right)=E_{t} v_{t+1}-v_{t}
$$

This equation implies that $v_{t}$ can be written as an expected discounted value of future $\log$ consumption, where the discount factor is $1 / \lambda_{1}=0.99$ at benchmark parameter values. The solution for $v_{t}$ takes the form $v_{t}=\eta_{v k} k_{t}+\eta_{v a} a_{t}$. For any parameter values $\eta_{v k}=\left(1-\lambda_{1}\right) /\left(1-\lambda_{1}-\lambda_{2}\right)=0.11$, the value of $\eta_{c k}$ in the $\sigma=0$ case. The elasticity with respect to technology, $\eta_{v a}$, varies with the persistence parameter $\phi$ but not with the intertemporal elasticity of substitution $\sigma$. For any $\sigma, \eta_{v a}$ is always equal to the value of $\eta_{c a}$ in the $\sigma=0$ case.

The interpretation of these results is straightforward. A $1 \%$ increase in capital increases the welfare of the representative agent by the same amount as an $\eta_{v k}=$ $0.11 \%$ permanent increase in consumption. $\eta_{v k}$ does not depend on the parameters of the agent's utility function, and it can be measured by looking at the permanent consumption increase that the agent optimally chooses in the $\sigma=0$ case. Similarly, a $1 \%$ increase in technology has the same welfare effect as an $\eta_{v a} \%$ permanent increase in consumption. $\eta_{v a}$ can be found by looking at the permanent consumption increase chosen in the $\sigma=0$ case. A $1 \%$ temporary increase in technology has a welfare effect equivalent to a $0.01 \%$ permanent increase in consumption, while a $1 \%$ permanent increase in technology has a much larger welfare effect equivalent to a $0.89 \%$ permanent increase in consumption.

\footnotetext{
${ }^{9}$ Campbell and Mankiw also argue that there is a predictable component of consumplion growth corrclated with predictable income growth, a phenomenon not modelled here.
} 
Figures $1 \mathrm{a}, 1 \mathrm{~b}$, and $1 \mathrm{c}$ illustrate the consequences of alternative parameter values for the dynamic response of output to technology shocks. In each case the initial response of output to a unit technology shock is just $\alpha=0.667$, the exponent on technology in the production function. Figure 1a shows responses to a technology shock with persistence $\phi=0.5$. The different response lines correspond to the five values of $\sigma$ studied in Table 1. None of the responses are very different from the underlying $A R(1)$ technology shock itself, because a transitory technology shock does not generate sufficient capital accumulation to have an important effect on output. To the extent that there is variation across $\sigma$ values, higher values give higher output initially but lower output in the long run. The reason is that an agent with a high value of $\sigma$ accumulates capital aggressively in response to the initial technology shock and then decumulates it rapidly when the technology shock disappears. An agent with a low value of $\sigma$, on the other hand, accumulates less capital but holds onto capital longer. In the extreme case $\sigma=0$, capital and output are permanently higher in the wake of a temporary technology shock.

Figures $1 \mathrm{~b}$ and $1 \mathrm{c}$ show output responses to technology shocks with persistence $\phi=0.95$ and $\phi=1$ respectively. Figure $1 \mathrm{~b}$ is similar to Figure $1 \mathrm{a}$ except that the different lines are further apart and output has a hump-shaped impulse response when $\sigma$ is sufficiently high. Capital accumulation can now make the medium-run output response higher than the short-run response. In Figure 1c the long-run output response is one for any positive value of $\sigma$, because of the cointegration property of the $\phi=1$ model discussed above. The adjustment to the long run is more rapid when $\sigma$ is larger; in the extreme case of infinite $\sigma$, the adjustment takes place in one period.

\section{More general technology processes and the "productivity slowdown"}

An important feature of the loglinear model is that the solutions for simple AR(1) technology shocks can be combined to obtain solutions for more complicated technology processes. Suppose that $\log$ technology $a_{t}$ is the sum of two components $a_{1 t}$ and $a_{2 t}$, each of which follows an $\operatorname{AR}(1)$ and is observed by the representative agent. It is straightforward to show that any endogenous variable $z_{t}$ obeys $z_{t}=$ $\eta_{z k} k_{t}+\eta_{z 1} a_{1 t}+\eta_{z 2} a_{2 t}$, where $\eta_{z 1}$ is the solution already obtained for $\eta_{z a}$ when $\log$ technology equals $a_{1 t}$, and $\eta_{z 2}$ is the solution for $\eta_{z a}$ when $\log$ technology equals 
$a_{2 t}$. This result generalizes in the obvious way to any number of separately observed components, which may have arbitrary correlations.

As an empirically relevant example, suppose that $a_{1 t}$ and $a_{2 t}$ have persistence parameters 0.95 and 1 respectively, and that their innovations have the same variance and are perfectly negatively correlated. Then a unit technology shock consists of a positive shock that decays at rate 0.95 , combined with a negative permanent shock. Such a shock causes technology (measured relative to its previous steady-state growth path) to decline gradually to a new, permanently lower level. It therefore approximates a "productivity slowdown" of the type experienced in the U.S. in the 1970's.

Figure 2 illustrates the effects of such a shock on output, consumption, and capital over a 10-year period. The figure assumes that $\sigma=1$. Technology is represented by a dotted line declining geometrically towards its new permanent level $1 \%$ below the old permanent level. The half-life of the technology decline is just over 3 years, and almost $90 \%$ of the decline is completed after 10 years. The long dashed line represents consumption. Because the technology decline is anticipated, permanent income considerations immediately reduce consumption by about $0.8 \%$. This initially leads to capital accumulation, as shown by the short dashed line for the capital stock. In less than 2 years, however, the capital stock starts to decline towards its new steadystate level. Because capital is high relative to technology during the transition to the new steady state, output (shown by a solid line) is also high relative to technology.

It is sometimes argued on permanent income grounds that a productivity slowdown should unambiguously increase saving. It is true that throughout the transition shown in the figure for the $\sigma=1$ case, consumption is unusually low relative to output. However this corresponds to faster rapital accumulation only for the first two years. After that, capital is decumulated despite the low consumption-output ratio because output is low relative to capital. This decumulation must occur (for any strictly positive $\sigma$ ), so that the economy can reach its new steady-state growth path with the same ratio of capital to technology that it had on the old growth path. Furthermore, if the elasticity of intertemporal substitution is large enough, consumption can actually rise relative to output at the onset of a productivity slowdown. This occurs for any value of $\sigma$ such that $\eta_{c a}$ declines with the persistence parameter $\phi$. Table 1 shows that an elasticity of intertemporal substitution of 5 is already large enough to produce this behavior. 


\section{Summary}

Before moving on to the variable-labor model, three characteristics of the fixedlabor model deserve particular note. First, capital accumulation has an important effect on the dynamics of the economy only when the underlying technology shock is persistent, lasting long enough for significant changes in capital to occur. This is very clear from the impulse responses plotted in Figures $1 \mathrm{a}, 1 \mathrm{~b}$, and $1 \mathrm{c} .^{10}$

Second, technology shocks do not have strong effects on ex post or ex ante real interest rates. The reason is that the marginal product of capital largely consists of undepreciated capital rather than the net output that is affected by technology shocks. The ex post real interest rate equals $\lambda_{3}$ times the log technology-capital ratio, and $\lambda_{3}=0.03$ at benchmark parameter values. Thus a $1 \%$ technology shock changes the ex post return to capital by only 3 basis points, or 12 basis points at an annual rate. The ex ante real interest rate is even more stable (and literally constant when the representative agent is risk-neutral) because capital accumulation lowers the marginal product of capital one period after a positive technology shock occurs, partially offsetting any persistent effects of the shock.

Third, capital accumulation alone does not generate a "multiplier" in the sense of an output response to a technology shock that is larger (in percentage terms) than the underlying shock itself. None of the output responses shown in Figures 1a, 1b, or 1c exceed one. This means that slower-than-normal technology growth can generate only slower-than-normal output growth and not actual declines in output. The model with fixed labor supply can explain output declines only by appealing to implausible declines in the level of technology.

${ }^{10}$ Blanchard and Fischer (1989) emphasize this point. 


\section{Variable Labor Supply}

I now consider two models with variable labor supply. These models leave the production function (2.1) unchanged, but allow labor input $N_{t}$ to be variable rather than constant and normalized to one. The capital accumulation equation (2.2) is also unchanged. However the objective function (2.3) now has a period utility function involving both consumption and leisure. The first model assumes that period utility is additively separable in consumption and leisure, while the second model has nonseparable period utility.

\section{An additively separable model}

In the first model, the representative agent has log utility for consumption and power utility for leisure:

$$
U\left(C_{t}, 1-N_{t}\right)=\log \left(C_{t}\right)+\theta \frac{\left(1-N_{t}\right)^{1-\gamma_{n}}}{1-\gamma_{n}}
$$

King, Plosser, and Rebelo (1988a) show that log utility for consumption is required to obtain balanced growth in a model with utility additively separable over consumption and leisure. The form of the utility function for leisure is not restricted by the balanced growth requirement. I use power utility for convenience and because it nests two popular special cases in the real business cycle literature: log utility for leisure in a model with divisible labor, and linear derived utility for leisure in a model with indivisible labor in which workers choose lotteries over hours worked rather than choosing hours worked directly (Hansen 1985, Rogerson 1988). The former case has $\gamma_{n}=1$, and the latter has $\gamma_{n}=0$. Christiano and Eichenbaum (1991) and King, Plosser, and Rebelo (1988a) explicitly compare these two special cases. By analogy with the notation of the previous section, I define $\sigma_{n} \equiv 1 / \gamma_{n}$, the elasticity of intertemporal substitution for leisure.

The first-order condition for intertemporal consumption choice remains the same as before, except that the gross marginal product of capital now depends on labor input as well as technology and the capital stock. Equation (2.5) is unchanged, but (2.4) becomes 


$$
R_{t+1} \equiv(1-\alpha)\left(\frac{A_{t+1} N_{t+1}}{K_{t+1}}\right)^{\alpha}+(1-\delta)
$$

The new feature of the variable-labor model is that there is now a static first-order condition for optimal choice of leisure relative to consumption at a particular date:

$$
\theta\left(1-N_{t}\right)^{-\gamma_{n}}=\frac{W_{t}}{C_{t}}=\alpha \frac{A_{t}^{\alpha}}{C_{t}}\left(\frac{\Gamma_{t}}{N_{t}}\right)^{1-\alpha}
$$

The marginal utility of leisure is set equal to the wage $W_{t}$ times the marginal utility of consumption. With $\log$ utility for consumption, this is just the wage divided by consumption. The wage in turn equals the marginal product of labor from the production function (2.1).

Analysis of the steady state from the previous section carries over directly to the variable-labor model. The relation (2.7) between $g$ and $r$, and the steady-state values of the ratios $A_{t} / K_{t}, Y_{t} / K_{t}$, and $C_{t} / Y_{t}$, are all the same as before.

\section{Fluctuations with separable utility}

Much of the analysis of fluctuations also carries over directly from the fixed labor supply model. The loglinear version of the capital accumulation equation (2.13) becomes

$$
k_{t+1} \approx \lambda_{1} k_{t}+\lambda_{2}\left(a_{t}+n_{t}\right)+\left(1-\lambda_{1}-\lambda_{2}\right) c_{t}
$$

where $\lambda_{1}$ and $\lambda_{2}$ are the same as before. (3.4) differs from (2.13) only in that $\lambda_{2}$ multiplies $n_{t}$ as well as $a_{t}$. The interest rate is now $r_{t+1}=\lambda_{3}\left(a_{t+1}+n_{t+1}-k_{t+1}\right)$, and the loglinear version of the intertemporal first-order condition (2.16) becomes

$$
E_{t} \Delta c_{t+1}=\lambda_{3} E_{t}\left(a_{t+1}+n_{t+1}-k_{t+1}\right)
$$

Equation (3.5) differs from (2.16) only in that $\sigma$ is now equal to one and $n_{t+1}$ appears in the equation. The technology shock process (2.18) also remains the same as before: 


$$
a_{t}=\phi a_{t-1}+\epsilon_{t} \text {. }
$$

These expressions contain an extra variable $n_{t}$, so to close the model one needs an extra equation which is provided by the static first-order condition (3.3). Loglinearizing in standard fashion (details are given in Appendix A), I find that

$$
n_{t}=\left(\frac{1-N}{N}\right) \sigma_{n}\left[\alpha a_{t}+(1-\alpha)\left(k_{t}-n_{t}\right)-c_{t}\right]
$$

where $N$ is the mean of labor supply. If, as Prescott (1986) asserts, households allocate one-third of their time to market activities, then $\mathrm{N}$ is one-third and $(1-N) / N=2$. I shall take this as a benchmark value.

It will be convenient to rewrite equation (3.7) to express labor supply in terms of capital, technology, and consumption:

$$
n_{t}=\nu\left[(1-\alpha) k_{t}+\alpha a_{t}-c_{t}\right]
$$

where

$$
\nu=\nu\left(\sigma_{n}\right) \equiv \frac{(1-N) \sigma_{n}}{N+(1-\alpha)(1-N) \sigma_{n}}
$$

The coefficient $\nu$ is a function of $\sigma_{n}$. It measures the responsiveness of labor supply to shocks that change the real wage or consumption, taking into account the fact that as labor supply increases the real wage is driven down. Thus even when utility for leisure is linear $\left(\sigma_{n}=\infty\right)$, the coefficient $\nu$ is not infinitely large. Instead, $\nu=1 /(1-\alpha)=3$ in this case. As the curvature of the utility function for leisure increases, $\nu$ falls and becomes zero when $\gamma_{n}$ is infinite. This corresponds to the fixed-labor case studied in the previous section.

Equation (3.8) can be used to substitute $n_{t}$ out of equations (3.4), (3.5), and (3.6). The system is then in the same form as before, and can be solved using the same approach. Once again log consumption is linear in log capital and log technology, with coefficients $\eta_{c k}$ and $\eta_{c a}$. The coefficient $\eta_{c k}$ solves the quadratic equation (2.24), where 
the coefficients $Q_{2}, Q_{1}$, and $Q_{0}$ are more complicated than before and are given in Appendix B. The solution for $\eta_{c a}$ can be obtained straightforwardly from $\eta_{c k}$ and the other parameters of the model. These solutions are the same as in the previous section when labor supply is completely inelastic so that $\nu=0$.

\section{Dynamic behavior of the economy}

The dynamics of the economy take the same form as in the fixed-labor model. Once again the log capital stock is a linear function of the first lags of log capital and $\log$ technology, $k_{t+1}=\eta_{k k} k_{t}+\eta_{k a} a_{t}$. But now the coefficients $\eta_{k k}$ and $\eta_{k a}$ are given by

$$
\begin{aligned}
& \eta_{k k} \equiv \lambda_{1}+\lambda_{2}(1-\alpha) \nu+\eta_{c k}\left[1-\lambda_{1}-\lambda_{2}(1+\nu)\right] \\
& \eta_{k a} \equiv \lambda_{2}(1+\alpha \nu)+\eta_{c a}\left[1-\lambda_{1}-\lambda_{2}(1+\nu)\right] .
\end{aligned}
$$

Log labor supply can also be written as a linear function of log capital and technology. Substituting the expression for consumption into (3.8), log labor supply is

$$
n_{t}=\nu\left(1-\alpha-\eta_{c k}\right) k_{t}+\nu\left(\alpha-\eta_{c a}\right) a_{t} \equiv \eta_{n k} k_{t}+\eta_{n a} a_{t} .
$$

Increases in capital raise the real wage by a factor $(1-\alpha)$; this stimulates labor supply, but capital also increases consumption by a factor $\eta_{c k}$, and this can have an offsetting effect. Similarly, increases in technology raise the real wage by a factor $\alpha$, but the stimulating effect on labor supply is offset by the effect $\eta_{c a}$ of technology on consumption. I use the notation $\eta_{n k}$ and $\eta_{n a}$ for the overall effects of capital and technology on labor supply.

Finally, $\log$ output can also be written as a linear function of log capital and technology:

$$
y_{t}=\left[(1-\alpha)+\alpha \nu\left(1-\alpha-\eta_{c k}\right)\right] k_{t}+\left[\alpha+\alpha \nu\left(\alpha-\eta_{c a}\right)\right] a_{t} \equiv \eta_{y k} k_{t}+\eta_{y a} a_{t}
$$


As before, this is an ARMA $(2,1)$ process. However capital and technology now affect output both directly (with coefficients $1-\alpha$ and $\alpha$ respectively) and indirectly through labor supply. The initial response to a technology shock is now $\alpha+\alpha \nu\left(\alpha-\eta_{\text {ca }}\right)$ rather than $\alpha$. Thus the variable-labor model can produce an amplified output response to technology shocks, even in the very short run.

Tables 2 and 3 illustrate the solution of the model for the same values of $\sigma_{n}$ and $\phi$ that were used for $\sigma$ and $\phi$ in Table 1 . Table 2 shows the consumption and capital elasticities that were reported in Table 1. Table 3 gives employnent and output elasticities.

When $\sigma_{n}=0$ (the first column of Tables 2 and 3 ), the model is the same as the model with fixed labor supply and log utility over consumption (the third column of Table 1). In this case the coefficients $\eta_{n k}$ and $\eta_{n a}$ are both zero. As $\sigma_{n}$ increases, the coefficient $\eta_{n k}$ becomes increasingly negative while $\eta_{n a}$ becomes increasingly positive. Thus an increase in capital lowers work effort because it increases consumption more than it increases the real wage. A positive technology shock increases work effort. The coefficient $\eta_{n k}$ is independent of the persistence of techmology $\phi$, but the coefficient $\eta_{n a}$ declines with $\phi$. The reason is that a persistent technology shock increases consumption more than a transitory one does (this is shown by the fact that $\eta_{c a}$ increases with $\phi$ in the table). The increase in consumption lowers the marginal utility of income and reduces work effort. Put another way, transitory technology shocks produce a stronger interternporal substitution effect in labor supply.

Once again several special cases of the model are worth attention. The random walk model for $\log$ technology $(\phi=1)$ is cointegrated just as in the fixed-labor model. Again we have $\eta_{c k}+\eta_{c a}=1$ and $\eta_{k k}+\eta_{k a}=1$, but also $\eta_{n k}+\eta_{n a}=0$. In this model labor supply effects are quite weak: Even with linear utility for leisure (an infinite $\sigma_{n}$ ), a $1 \%$ increase in technology stimulates only a $0.49 \%$ increase in work effort. As mentioned above, the case $\sigma_{n}=0$ is the fixed-labor model with $\log$ utility for consumption. The opposite extreme case $\sigma_{n}=\infty$ solves relatively easily because $(1-\alpha) \nu=1$ so the intercept term $Q_{0}$ in the equation for $\eta_{c k}$ is zero and this equation becomes linear. However the coefficients obtained in this case do not have any straightforward interpretation.

Tables 2 and 3 can also be used to calculate the elasticities of gross factor returns with respect to capital and technology. The ex post real interest rate $r_{t+1}=\lambda_{3}\left(a_{t+1}+\right.$ $\left.n_{l+1}-k_{l+1}\right)$, so its response to capital is $\lambda_{3}\left(\eta_{n k}-1\right)$ and its response to technology 
is $\lambda_{3}\left(1+\eta_{n a}\right)$. These responses are small, just as they were in the fixed-labor model. The largest possible effect of a $1 \%$ technology shock on the ex post real interest rate is 8 basis points at a quarterly rate, or 32 basis points at an annual rate, when the technology shock is purely temporary and the utility function is linear in leisure. The ex ante real interest rate is also stable for similar reasons.

The log real wage rate equals $y_{t}-n_{t}$, so its response to capital is $\eta_{y k}-\eta_{n k}$ and its response to technology is $\eta_{y a}-\eta_{n a}$. Inspection of Table 3 shows that the elasticity of the wage with respect to technology is smallest when utility is linear in leisure. In this case (the right hand column of Table 3 ) the real wage elasticity is the same as the consumption elasticity $\eta_{c a}$, because linear utility in leisure fixes the wage-consumption ratio. Depending on its persistence, a $1 \%$ technology shock can raise the real wage by $0.11 \%$ to $0.50 \%$. Somewhat greater real wage effects are obtained when labor supply is inelastic. In the extreme fixed-labor case (the left hand column of Table 3), a $1 \%$ transitory or persistent technology shock raises the real wage by $0.67 \%$. As Christiano and Eichenbaum (1991) emphasize, in this model the marginal product of labor is proportional to the average product, so elasticities for labor productivity are the same as those for the real wage.

Variable labor supply has important implications for the elasticity of output with respect to technology, $\eta_{y c}$. Recall that when labor supply is fixed $(\nu=0)$, this elasticity is just $\alpha=0.667$. With variable labor supply, $\eta_{y a}=\alpha+\alpha \nu\left(\alpha-\eta_{c a}\right)$. This can exceed one, reaching a maximum of 1.78 when $\nu=3$ and $\phi=0$. The elasticity falls with $\phi$, however, and when $\phi=1$ it cannot exceed 0.99 . This is important because an elasticity greater than one allows absolute declines in output to be generated by positive but slower than normal growth in technology; this is surely more plausible than the notion that there are absolute declines in technology. The elasticity is illustrated in Figure 3, a contour plot of $\eta_{y a}$ against the parameters $\nu$ and $\phi$.

\section{A nonseparable model}

An alternative specification that is consistent with balanced growth is the nonadditively-separable Cobb-Douglas utility function,

$$
\begin{gathered}
U\left(C_{t}, N_{t}\right)=\left[C_{t}^{\rho}\left(1-N_{t}\right)^{1-\rho}\right]^{1-\gamma} /(1-\gamma) . \\
-24-
\end{gathered}
$$


This is used by Eichenbaum, Hansen, and Singleton (1988) and Prescott (1986). When $\gamma=\sigma=1$, this utility function is the same as the additively separable utility function with $\sigma_{n}=1$.

The steady state for this model is similar to that for the previous model. The equation relating the growth rate, the utility discount rate, and the interest rate is slightly altered from (2.7) to

$$
g=\frac{\log (\beta)+r}{1-\rho(1-\gamma)}
$$

However the steady-state output-capital and consumption-output ratios are the same as before.

The approximate loglinear model of fluctuations has the same capital accumulation equation as before. The static first-order condition for optimal labor supply does not depend on the curvature of the utility function and is

$$
n_{t}=\nu(1)\left[(1-\alpha) k_{t}+\alpha a_{t}-c_{t}\right]
$$

where $\nu(1)$ is given by (3.9) setting $\sigma_{n}=1$. The intertemporal first-order condition is somewhat more complicated than in the separable case. It takes the form

$$
[1-\rho(1-\gamma)] E_{t} \Delta c_{t+1}+(1-\rho)(1-\gamma)\left(\frac{N}{1-N}\right) E_{t} \Delta n_{t+1}=\lambda_{3} E_{t}\left(a_{t+1}+n_{t+1}-k_{t+1}\right)
$$

Solution of the nonseparable model proceeds in standard fashion, described explicitly in Appendix B. Consumption and capital elasticities for this model are given in Table 4, and employment and output elasticities are given in Table 5. Comparing Table 4 with Table 2 , the nonseparable model allows a much wider range of consumption elasticities because it does not fix the curvature of the utility of consumption. However this does not have a major effect on output elasticities. Comparing Table 5 with Table 3 , the output response to technology shocks covers roughly the same range in the nonseparable model as it did in the separable model. The largest possible response 
to a temporary technology shock is slightly smaller in the nonseparable model, but the largest possible response to a permanent shock is slightly larger. This means that the nonseparable model can produce a multiplier slightly greater than one even when technology shocks are permanent.

\section{The productivity slowdown with variable labor}

Just as in the fixed-labor model, the solutions obtained above can be combined to describe responses to more general technology processes. Figure 4 shows the response of the economy to a productivity slowdown (a positive shock with persistence 0.95 , combined with a negative shock with persistence 1), under the assumption of log utility for consumption and leisure. As noted above, this utility specification can be obtained from the separable model with $\sigma_{n}=1$, or from the nonseparable model with $\sigma=1$.

The dynamics shown in figure 4 are similar to those in figure 2. Consumption drops immediately, which leads to a period of capital accumulation before capital gradually declines to its new steady-state value. There are however two new features in figure 4. First, in the later stages of the transition the consumption-output ratio is above its steady-state level because low real interest rates stimulate consumption. Second and more important, the initial drop in consumption is accompanied by an increase in work effort (since the technology shock has no immediate impact on the real wage, and the marginal utility of consumption is higher). This raises output initially, and leads to a more pronounced accumulation of capital than in figure 2. Output falls below its old steady-state level 1 year after the initial shock, but capital does not fall below this level until 4 years after the shock. It is straightforward to verify from tables 3 and 5 that this effect is robust: The initial output response to the productivity slowdown is positive for any possible value of $\sigma$ or $\sigma_{n}$.

This example illustrates an important point. In a model with variable labor supply, the responses of employment and output to a technology shock decline with the persistence of that shock. If the shock is more persistent than a random walk, so that its ultimate effect is larger than its initial effect, then it is possible to get a perverse initial response of employment and output. The reason is that a highly persistent shock has a large initial effect on the marginal utility of consumption relative to its initial effect on the real wage. 


\section{Government Consumption}

The stochastic growth model can also be subjected to other types of shocks. In this section I briefly review how the solution technique of this paper can be used to study the effects of government spending. For simplicity I assume that taxes are lump-sum and that government consumption does not enter the utility function of the representative agent. Then all first-order conditions are the same as before and government spending affects only the capital accumulation equation. This becomes

$$
K_{t+1}=(1-\delta) K_{t}+Y_{t}-C_{t}-X_{t}
$$

where $X_{t}$ is the level of government consumption. Note that the time path of spending is what is relevant, not the time path of taxes, because Ricardian equivalence holds in this model.

The steady state of the economy with government spending is very similar to the steady state described previously. In particular the relation between the growth rate and the interest rate is the same, and the output-capital ratio is the same. The ratio of private plus government consumption to output is also unchanged, which means that the private consumption-output ratio is reduced by the government consumptionoutput ratio.

The addition of government spending does not have an important effect on the economy's response to technology shocks. The only effect comes from the fact that the loglinear approximate capital accumulation equation is now

$$
k_{t+1} \approx \lambda_{1} k_{t}+\lambda_{2}\left(a_{t}+n_{t}\right)+\lambda_{4} x_{t}+\left(1-\lambda_{1}-\lambda_{2}-\lambda_{4}\right) c_{t}
$$

where

$$
\lambda_{4} \equiv \frac{-(r+\delta) X / Y}{(1-\alpha)(1+g)}
$$

If the steady-state government consumption-output ratio is 0.2 , then $\lambda_{4}=0.02$ at the benchmark values of the other parameters. The effect of log consumption on log capital 
is therefore reduced by 0.02 . The previous analysis of technology shocks applies if one replaces $\left(1-\lambda_{1}-\lambda_{2}\right)$ by $\left(1-\lambda_{1}-\lambda_{2}-\lambda_{4}\right)$ throughout.

Similar reasoning shows that the technology shock process does not affect the economy's response to government spending shocks. For simplicity, I shall therefore ignore technology shocks in the remainder of this section. Assuming an AR(1) process for government spending, the loglinear model with separable utility over consumption and leisure becomes (4.2) with $a_{t}$ set to zero, together with

$$
\begin{gathered}
E_{t} \Delta c_{t+1}=\lambda_{3} E_{t}\left(n_{t+1}-k_{t+1}\right), \\
x_{t}=\phi x_{t-1}+\epsilon_{t}, \\
n_{t}=\nu\left[(1-\alpha) k_{t}-c_{t}\right],
\end{gathered}
$$

where $\nu=\nu\left(\sigma_{n}\right)$ is as defined in equation (3.9).

This model can be solved in the standard fashion. (Details are given in Appendix B.) Once the elasticities of consumption $\eta_{c k}$ and $\eta_{c x}$ have been found, the other elasticities follow straightforwardly from $(4.2),(4.6)$, and the production function. Table 6 gives the consumption and capital elasticities and Table 7 gives the employment and output elasticities for the standard range of parameter values.

Table 6 shows that private consumption falls when government consumption increases. It falls by more when government consumption is more persistent, for permanent income reasons. It falls by less when labor supply is more elastic, for then increased labor supply (shown in Table 7) can meet some of the increased tax burden. Labor supply increases with government consumption, since the real wage is unchanged by a government consumption shock and the marginal utility of consumption increases. Labor supply increases by more when labor supply is more elastic, and when a more persistent change in government consumption leads to a greater decline in consumption and increase in the marginal utility of consumption.

It follows from this that the output effect of government consumption increases with the persistence of government consumption. This is directly contrary to the 
claims of Barro (1981) and Hall (1980). Aiyagari, Christiano, and Eichenbaum (1990) and Baxter and King (1990a) have already established the correct result in a real business cycle framework, but the analytical approach here may make the result more transparent. Figure 5 is a contour plot of the output elasticity against the persistence $\phi$ of government consumption and the parameter $/$ measuring the elasticity of labor supply. As $\phi$ and $\nu$ approach their maximum possible values, the output elasticity approaches its maximum of 0.29 . Dividing by the steady-state ratio of government spending to output (assumed to be 0.2 ), this implies that an extra dollar of government consumption generates at most 1.45 dollars of output. The elasticity declines very rapidly with $\phi$; even when $\phi=0.95$ the largest possible elasticity is only 0.18 , implying that an extra dollar of government spending generates less than an extra dollar of output. 


\section{Conclusion}

In this paper I have argued that an analytical approach to the stochastic growth model helps to generate important insights. I have assumed plausible benchmark values for model parameters describing the steady state growth path of the economy, and have used an approximate analytical solution to explore the effects of other parameters - the intertemporal elasticity of substitution in consumption, the elasticity of labor supply, the persistence of technology shocks, and the persistence of government consumption shocks - on the dynamic behavior of the model. Some of the main results of this exploration are as follows.

First, a model with fixed labor supply and a very small intertemporal elasticity of substitution in consumption is a general equilibrium version of the permanent income theory of consumption. It has many of the properties discussed informally by Fama (1991); in particular, temporary technology shocks cause temporary fluctuations in output and investment, but not in consumption.

Second, with variable labor supply it is possible for the elasticity of output with respect to technology shocks to exceed one. This seems to be important if output fluctuations are to be explained by technology shocks, because it permits output to decline when technology grows more slowly than normal; with a smaller than unit elasticity, on the other hand, technology declines are needed to produce output declines. Unfortunately, an elasticity greater than one depends both on highly elastic labor supply (as is well understood) and on low persistence of technology shocks. If technology is a random walk and utility is separable over consumption and leisure, then even with infinitely elastic labor supply the output elasticity cannot exceed one.

Third, the basic analysis in this paper assumes an AR(1) log technology shock. However different solutions can be combined to obtain the solution for any linear combination of $A R(1)$ processes. This enables me to calculate the response of the economy to a highly persistent technology shock of the type that may have occurred in the "productivity slowdown" of the 1970's. The output elasticity with respect to such a shock can actually be negative, because low technology growth today signals even lower technology (relative to trend) in the future, and this stimulates output today rather than dampening it.

Fourth, all the models examined have the feature that expected and realized marginal products of capital are extremely stable. A $1 \%$ technology shock moves the 
realized marginal product of capital by no more than 12 basis points (at an annual rate) in a fixed-labor model, and by no more than 32 basis points in a separable variablelabor model; and for most parameter values the marginal product of capital is much less responsive to technology shochs. The reason for this stability is that most of the marginal product of capital is undepreciated capital rather than the output which is affected by technology. This feature of the stochastic growth model makes it hard for the model to explain the observed variability of real interest rates.

Einally, the paper follows recent work showing that permanent shocks to government consumption have larger output effects than temporary shocks. With sufficiently elastic labor supply and sufficiently persistent government consumption, it is possible for a dollar of government spending to stimulate more than a dollar of additional output; however this requires an $\mathrm{AR}(1)$ process for government spending with a persistence parameter above 0.96 .

The analytical approach of this paper can be adapted to study a number of other interesting issues. It should be straightforward, for example, to allow for convex adjustment costs in investment (Baxter and Crucini 1989), technology "spillovers" (Baxter and King 1990b), distortionary taxation (Baxter and King 1990a, Greenwood and Huffman 1991, McGrattan 1991), or "rule-of-thumb" consumption behavior (Campbell and Mankiw 1989). More challenging will be to allow for real and nominal macroeconomic rigidities of the type emphasized by recent work in the Keynesian tradition. Ultimately, a stochastic growth model incorporating such rigidities holds out the promise of a new synthesis in macroeconomics. 


\section{Appendix A: Taylor Approximations}

To obtain equation (2.13) I proceed as follows. On the left hand side of (2.12) is the nonlinear function $f_{1}\left(\Delta k_{t+1}\right) \equiv \log \left[\exp \left(\Delta k_{t+1}\right)-(1-\delta)\right]$. This is approximated as $f_{1}\left(\Delta k_{t+1}\right) \approx f_{1}(g)+f_{1}^{\prime}(g)\left(\Delta k_{t+1}-g\right)$, where

$$
f_{1}^{\prime}(g)=\frac{\exp (g)}{\exp (g)-(1-\delta)} \approx \frac{1+g}{\delta+g} .
$$

On the right hand side of (2.12) is the nonlinear function $f_{2}\left(c_{t+1}-y_{t+1}\right) \equiv \log [1-$ $\left.\exp \left(c_{t}-y_{t}\right)\right]{ }^{11}$ This is approximated as $f_{2}\left(c_{t+1}-y_{t+1}\right) \approx f_{2}(c-y)+f_{2}^{\prime}(c-y)\left(c_{t+1}-\right.$ $\left.y_{t+1}-(c-y)\right)$, where

$$
f_{2}^{\prime}(c-y) \approx 1-\frac{r+\delta}{(1-\alpha)(g+\delta)}
$$

Substituting these approximations into (2.12) and dropping constants, I obtain a loglinear approximate accumulation equation,

$$
\left(\frac{1+g}{\delta+g}\right) \Delta k_{t+1} \approx y_{t}-k_{t}+\left[1-\frac{r+\delta}{(1-\alpha)(g+\delta)}\right]\left(c_{t}-y_{t}\right)
$$

The $\log$ production function (2.11) can be used to substitute out $y_{t}$ from this equation, yielding (2.13).

To obtain equation (2.16), I take logs of (2.4) to obtain

$$
r_{t+1}=f_{3}\left(a_{t+1}-k_{t+1}\right) \equiv \log \left[1-\delta+(1-\alpha) \exp \left(\alpha a_{t+1}-\alpha k_{t+1}\right)\right]
$$

The function $f_{3}\left(a_{t+1}-k_{t+1}\right)$ is approximated as $f_{3}\left(a_{t+1}-k_{t+1}\right) \approx f_{3}(a-k)+f_{3}^{\prime}(a-$ $k)\left(a_{t+1}-k_{t+1}-(a-k)\right)$, where

$$
f_{3}^{\prime}(a-k) \approx \frac{\alpha(r+\delta)}{1+r}
$$

${ }^{11}$ Connoisseurs will recognize this as the function approximated in Campbell and Shiller (1988) and Campbell (1990). 
Substituting these expressions into (2.15) yields (2.16).

To obtain equation (2.33), I proceed as follows. Bellman's equation states that

$$
V_{t}^{1-\gamma}=\operatorname{Max} C_{t}^{1-\gamma}+\beta E_{t} V_{t+1}^{1-\gamma}
$$

It is straightforward to show that in steady state,

$$
\frac{V_{t}^{1-\gamma}}{C_{t}^{1-\gamma}}=\frac{r-g}{1+r}
$$

Taking logs of (A.6) and dropping constants, I obtain $f_{2}\left((1-\gamma)\left(c_{t}-v_{t}\right)\right) \equiv \log (1-$ $\left.\exp \left[(1-\gamma)\left(c_{t}-v_{t}\right)\right]\right)=(1-\gamma) E_{t}\left(v_{t+1}-v_{t}\right)$. On the left hand side is the same function approximated above in (A.2), where now

$$
f_{2}^{\prime}((1-\gamma)(c-v)) \approx-\frac{r-g}{1+g}=1-\lambda_{1}
$$

To obtain equation (3.7) I take logs of (3.3), dropping constants, and obtain

$$
-\gamma_{n} \log \left[1-\exp \left(n_{t}\right)\right]=\alpha a_{t}+(1-\alpha)\left(k_{t}-n_{t}\right)-c_{t}
$$

On the left hand side of (A.9) is the nonlinear function $f_{4}\left(n_{t}\right) \equiv \log \left[1-\exp \left(n_{t}\right)\right]$. This is approximated as $f_{4}\left(n_{t}\right) \approx f_{4}(n)+f_{4}^{\prime}(n)\left(n_{t}-n\right)$, where

$$
f_{4}^{\prime}(n)=-\frac{\exp (n)}{1-\exp (n)} \approx-\frac{N}{1-N}
$$

Substituting into (A.9) and rearranging, I obtain (3.7) and (3.8). 


\section{Appendix B: Complete Solutions for the Variable-Labor Models}

In the separable variable-labor model with technology shocks, the solution for $\eta_{c k}$ is the solution to the quadratic equation (2.24), $Q_{2} \eta_{c k}^{2}+Q_{1} \eta_{c k}+Q_{0}=0$, where now

$$
\begin{aligned}
& Q_{2} \equiv\left[1+\lambda_{3} \nu\right]\left[1-\lambda_{1}-\lambda_{2}(1+\nu)\right] \\
& Q_{1} \equiv\left[1+\lambda_{3} \nu\right]\left[\lambda_{1}+\lambda_{2}(1-\alpha) \nu\right]-\lambda_{3}[(1-\alpha) \nu-1]\left[1-\lambda_{1}-\lambda_{2}(1+\nu)\right]-1 \\
& Q_{0} \equiv-\lambda_{3}[(1-\alpha) \nu-1]\left[\lambda_{1}+\lambda_{2}(1-\alpha) \nu\right]
\end{aligned}
$$

The solution is given by the quadratic formula $(2.26)$, as before. Given $\eta_{c k}$, the solution for $\eta_{c a}$ follows as

$$
\eta_{c a}=\frac{(1+\alpha \nu)\left[\lambda_{3} \phi-\lambda_{2}\left\{\eta_{c k}\left(1+\lambda_{3} \nu\right)-\lambda_{3}((1-\alpha) \nu-1)\right\}\right]}{\left\{\eta_{c k}\left(1+\lambda_{3} \nu\right)-\lambda_{3}((1-\alpha) \nu-1)\right\}\left\{1-\lambda_{1}-\lambda_{2}(1+\nu)\right\}-\left\{1-\phi\left(1+\lambda_{3} \nu\right)\right\}}
$$

In the nonseparable variable-labor model with technology shocks, the solution for consumption elasticities is more complicated. It is easiest to state by defining some intermediate parameters: 


$$
\begin{aligned}
\psi & \equiv(1-\rho)(1-\gamma)\left(\frac{N}{1-N}\right) \nu(1) \\
\xi_{1} & \equiv 1-\rho(1-\gamma)-\psi+\lambda_{3} \nu(1) \\
\xi_{2} & \equiv-(1-\rho(1-\gamma)-\psi) \\
\xi_{3} & \equiv \psi(1-\alpha)-\lambda_{3}[\nu(1)(1-\alpha)-1] \\
\xi_{4} & \equiv-\psi(1-\alpha) \\
\xi_{5} & \equiv \psi \alpha-\lambda_{3}[1+\nu(1) \alpha] \\
\xi_{6} & \equiv-\psi \alpha \\
\kappa_{1} & \equiv \lambda_{1}+\lambda_{2}(1-\alpha) \nu(1) \\
\kappa_{2} & \equiv 1-\lambda_{1}-\lambda_{2}(1+\nu(1)) \\
\kappa_{3} & \equiv \lambda_{2}(1+\alpha \nu(1)) .
\end{aligned}
$$

Then again $\eta_{c k}$ solves $Q_{2} \eta_{c k}^{2}+Q_{1} \eta_{c k}+Q_{0}=0$, where now

$$
Q_{2} \equiv \xi_{1} \kappa_{2}, \quad Q_{1} \equiv \xi_{1} \kappa_{1}+\xi_{3} \kappa_{2}+\xi_{2}, \quad Q_{0} \equiv \xi_{3} \kappa_{1}+\xi_{4}
$$

The solution is given by the quadratic formula (2.26), as before. Given $\eta_{c k}$, the solution for $\eta_{c a}$ follows as

$$
\eta_{c a}=-\frac{\phi \xi_{5}+\xi_{6}+\kappa_{3}\left[\xi_{1} \eta_{c k}+\xi_{3}\right]}{\phi \xi_{1}+\xi_{2}+\kappa_{2}\left[\xi_{1} \eta_{c k}+\xi_{3}\right]} .
$$

In the separable variable-labor model with government consumption shocks, the quadratic equation for $\eta_{c k}$ has the same parameters as before, except that $1-\lambda_{1}-$ $\lambda_{2}(1+\nu)$ is replaced by $1-\lambda_{1}-\lambda_{2}(1+\nu)-\lambda_{4}$ everywhere. The solution for $\eta_{c x}$ follows as

$$
\eta_{c x}=\frac{\lambda_{4}\left[\lambda_{3}\left((1-\alpha) \nu-1-\nu \eta_{c k}\right)-\eta_{c k}\right]}{\phi\left(1+\lambda_{3} \nu\right)-1-\left[\lambda_{3}\left((1-\alpha) \nu-1-\nu \eta_{c k}\right)-\eta_{c k}\right]\left(1-\lambda_{1}-\lambda_{2}(1+\nu)-\lambda_{4}\right)} .
$$




\section{Bibliography}

Aiyagari, S. Rao, Lawrence J. Christiano, and Martin Eichenbaum, 1990, "The Output, Employment, and Interest Rate Effects of Government Consumption", National Bureau of Economic Research Working Paper No. 3330.

Barro, Robert J., 1981, "Output Effects of Government Purchases", Journal of Political Economy 89, 1086-1121.

Barro, Robert J,, 1990, Macroeconomics, 3rd ed., John Wiley: New York, NY.

Baxter, Marianne and Robert G. King, 1990a, "Fiscal Policy in General Equilibrium", Working Paper No. 244, University of Rochester.

Baxter, Marianne and Robert G. King, 1990b, "Productive Externalities and Cyclical Volatility", Working Paper No. 245, University of Rochester.

Baxter, Marianne and Mario J. Crucini, 1985, "Explaining Saving/Investment Correlations", unpublished paper, University of Rochester.

Blanchard, Olivier J. and Stanley Fischer, 1989, Lectures on Macroeconomics, MIT Press: Cambridge, Mass.

Campbell, John Y., 1990, "Intertemporal Asset Pricing Without Consumption", unpublished paper, Princeton University.

Campbell, John Y. and N. Gregory Mankiw, 1989, "Consumption, Income, and Interest Rates: Reinterprcting the Time-Series Evidence", NBER Macroeconomics Annual $1989,185-216$.

Campbell, John Y. and Robert J. Shiller, 1988, "The Dividend-Price Ratio and Expectations of Future Dividends and Discount Factors", Review of Financial Studies 1, 195-228.

Christiano, Lawrence J., 1988, "Why Does Inventory Investment Fluctuate So Much?", Journal of Monetary Economics 21, 247-280.

Christiano, Lawrence J., 1989, "Solving a Particular Growth Model by Linear Quadratic Approximation and by Value Function Iteration", Institute for Empirical Macroeconomics Discussion Paper 9, Federal Reserve Bank of Minneapolis.

Christiano, Lawrence J. and Martin Eichenbaum, 1991a, "Current Real Business Cycle Theories and Aggregate Labor Market Fluctuations", forthcoming, American Economic Review.

Christiano, Lawrence J. and Martin Eichenbaum, 1991b, "Liquidity Effects, Monetary Policy and the Business Cycle", unpublished paper, Federal Reserve Bank of Minneapolis and Northwestern University.

Christiano, Lawrence J., Martin Eichenbaum, and David Marshall, 1991, "The Permanent Income Hypothesis Revisited", Econometrica 59, 397-423.

Eichenbaum, Martin, Lars P. Hansen, and Kenneth J. Singleton, 1988, "A Time Series Analysis of Representative Agent Models of Consumption and Leisure Choice Under Uncertainty", Quarterly Journal of Economics 103, 51-78. 
Fama, Eugene F., 1991, "Transitory Variation in Investment and Output", unpublished paper, Graduate School of Business, University of Chicago.

Flavin, Marjorie A., 1981, "The Adjustment of Consumption to Changing Expectations About Future Income", Journal of Political Economy 89, 974-1009.

Greenwood, Jeremy and Gregory W. Huffman, 1991, "Tax Analysis in a Real BusinessCycle Model: On Measuring Harberger Triangles and Okun Gaps", Journal of Monetary Economics 27, 167-190.

Hall, Robert E., 1978, "Stochastic Implications of the Life Cycle-Permanent Income Hypothesis: Theory and Evidence", Journal of Political Economy 86, 971-987.

Hall, Robert E., 1980, "Labor Supply and Aggregate Fluctuations", in Karl Brunner and Allan Meltzer eds. On the State of Macroeconomics, Carnegie-Rochester Conference Series on Public Policy Vol. 12, Amsterdam: North-Holland.

Hall, Robert E., 1988, "Intertemporal Substitution in Consumption", Journal of Political Economy 96, 339-357.

Hansen, Gary D., 1985, "Indivisible Labor and the Business Cycle", Journal of Monetary Economics, 16, 309-328.

Hansen, Lars P. and Thomas J. Sargent, 1991, Recursive Linear Models of Dynamic Economies, forthcoming, Princeton University Press: Princeton, NJ.

Kimball, Miles S., 1990, "Real Business Cycle Analytics", unpublished paper, University of Michigan.

King, Robert G., 1991, "Money and Business Cycles", unpublished paper, University of Rochester.

King, Robert G., Charles I. Plosser, and Sergio T. Rebelo, 1987, "Production, Growth and Business Cycles: Technical Appendix", unpublished paper, University of Rochester.

King, Robert G., Charles I. Plosser, and Sergio T. Rebelo, 1988a, "Production, Growth and Business Cycles I. The Basic Neoclassical Model", Journal of Monetary Economics 21, 195-232.

King, Robert G., Charles I. Plosser, and Sergio T. Rebelo, 1988b, "Production, Growth and Business Cycles II. New Directions", Journal of Monetary Economics 21, 309342 .

King, Robert G., Charles I. Plosser, James H. Stock, and Mark W. Watson, 1991, "Stochastic Trends and Economic Fluctuations", American Economic Review 81, $819-840$.

Kocherlakota, Narayana, 1988, "In Defense of the Time and State Separable UtilityBased Asset Pricing Model", unpublished paper, Northwestern University.

Kydland, Finn E. and Edward C. Prescott, 1982, "Time to Build and Aggregate Fluctuations", Econometrica 50, 1345-1370.

Long, John B. and Charles I. Plosser, 1983, "Real Business Cycles", Journal of Political Economy 91, 39-69. 
McCallum, Bennett T., 1989, "Real Business Cycle Models", in Robert J. Barro ed. Modern Business Cycle Theory 16-50, Harvard University Press: Cambridge, Mass.

McGrattan, Ellen R., 1991, "The Macroeconomic Effects of Distortionary Taxation", Institute for Empirical Macroeconomics Discussion Paper 37, Federal Reserve Bank of Minneapolis.

Plosser, Charles I., 1989, "Understanding Real Business Cycles", Journal of Economic Perspectives 3, 51-77.

Prescott, Edward C., 1986, "Theory Ahead of Business Cycle Measurement", Federal Reserve Bank of Minneapolis Quarterly Review 10, 9-22.

Rogerson, Richard, 1988, "Indivisible Labor, Lotteries, and Equilibrium", Journal of Monetary Economics 21, 3-17.

Samuelson, Paul A., 1939, "Interactions Between the Multiplier Analysis and the Principle of Acceleration", Review of Economics and Statistics 51, 239-246.

Simon, Julian L., 1990, "Great and Almost-Great Magnitudes in Economics", Journal of Economic Perspectives 4, 149-156.

Summers, Lawrence H., 1986, "Some Skeptical Observations on Real Business Cycle Theory", Federal Reserve Bank of Minneapolis Quarterly Review 10, 23-27.

Taylor, John B. and Harald Uhlig, 1990, "Solving Nonlinear Stochastic Growth Models: A Comparison of Alternative Solution Methods", Journal of Business and Economic Statistics 8, 1-17. 
Table 1

Consumption and Capital Elasticities for the Fixed-Labor Model with Technology Shocks

\begin{tabular}{|c|c|c|c|c|c|}
\hline \multirow[b]{2}{*}{$\phi=$} & \multicolumn{5}{|c|}{$\sigma=$} \\
\hline & 0 & 0.2 & 1 & 5 & $\infty$ \\
\hline \multirow{2}{*}{0.00} & $0.11,0.01$ & $0.30,0.02$ & $0.59,0.05$ & $1.21, \quad 0.10$ & 11.30 \\
\hline & $1.00,0.08$ & $0.98,0.08$ & $0.96,0.07$ & $0.90, \quad 0.07$ & 0.00 \\
\hline \multirow{2}{*}{0.50} & $0.11,0.02$ & $0.30,0.04$ & $0.59,0.06$ & $1.21, \quad 0.06$ & $11.30,-4.69$ \\
\hline & $1.00,0.08$ & $0.98,0.07$ & $0.96,0.07$ & $0.90, \quad 0.07$ & 0.00 \\
\hline \multirow{2}{*}{0.95} & $0.11,0.15$ & $0.30,0.25$ & $0.59,0.23$ & $1.21,-0.12$ & $11.30,-9.70$ \\
\hline & $1.00,0.07$ & $0.98,0.06$ & $0.96,0.06$ & $0.90, \quad 0.09$ & 0.00 \\
\hline \multirow{2}{*}{1.00} & $0.11,0.89$ & $0.30,0.70$ & $0.59,0.41$ & $1.21,-0.21$ & $11.30,-10.30$ \\
\hline & $1.00,0.00$ & $0.98,0.02$ & $0.96,0.04$ & $0.90, \quad 0.10$ & 0.00 \\
\hline
\end{tabular}

The model is $c_{t}=\eta_{c k} k_{t}+\eta_{c a} a_{t}, k_{t+1}=\eta_{k \cdot k} k_{t}+\eta_{k a} a_{t}$.

This table reports $\eta_{c k}$ : $\eta_{c a}$ above $\eta_{k k}, \eta_{k a}$. 
Table 2

Consumption and Capital Elasticities for the Separable Variable-Labor Model with Technology Shocks

\begin{tabular}{c|c|c|c|c|c|c|}
\multicolumn{1}{c}{$\phi=$} & $0,0.00$ & $0.2,0.35$ & $1,1.20$ & $5,2.31$ & $\infty, 3.00$ \\
\hline \multirow{2}{*}{0.00} & $0.59,0.05$ & $0.57,0.05$ & $0.54,0.07$ & $0.51,0.10$ & $0.50,0.11$ \\
& $0.96,0.08$ & 0.95, & 0.09 & $0.94,0.13$ & $0.93,0.18$ & $0.93,0.20$ \\
\hline \multirow{2}{*}{0.50} & $0.59,0.06$ & $0.57,0.08$ & $0.54,0.10$ & $0.51,0.12$ & $0.50,0.14$ \\
& $0.96,0.07$ & $0.95,0.09$ & $0.94,0.13$ & $0.93,0.17$ & $0.93,0.19$ \\
\hline \multirow{2}{*}{0.95} & $0.59,0.23$ & $0.57,0.25$ & $0.54,0.29$ & $0.51,0.33$ & $0.50,0.35$ \\
& $0.96,0.06$ & $0.95,0.07$ & $0.94,0.09$ & $0.93,0.11$ & $0.93,0.12$ \\
\hline \multirow{2}{*}{1.00} & $0.59,0.41$ & $0.57,0.43$ & $0.54,0.46$ & $0.51,0.49$ & $0.50,0.50$ \\
& $0.96,0.04$ & $0.95,0.05$ & $0.94,0.06$ & $0.93,0.07$ & $0.93,0.07$ \\
\hline
\end{tabular}

The model is $c_{t}=\eta_{c k} k_{t}+\eta_{c a} a_{t}, k_{t+1}=\eta_{k k} k_{t}+\eta_{k a} a_{t}$.

This table reports $\eta_{c k}, \eta_{c a}$ above $\eta_{k k}, \eta_{k a}$.

Table 3

Employment and Output Elasticities for the Separable Variable-Labor Model with Technology Shocks

\begin{tabular}{c|c|c|r|r|r|}
\multicolumn{1}{c}{$\phi=$} & \multicolumn{1}{|c}{$\sigma_{n}, \nu\left(\sigma_{n}\right)=$} \\
\hline \multirow{2}{*}{0.00} & $0,0.00$ & \multicolumn{1}{c}{$0.2,0.35$} & \multicolumn{1}{c}{$1,1.20$} & \multicolumn{1}{c}{$5,2.31$} & $\infty, 3.00$ \\
\hline \multirow{2}{*}{0.50} & $0.00,0.00$ & $-0.08,0.22$ & $-0.24,0.71$ & $-0.40,1.32$ & $-0.49,1.67$ \\
& $0.33,0.67$ & $0.28,0.81$ & $0.17,1.14$ & $0.06,1.54$ & $0.01,1.78$ \\
\hline \multirow{2}{*}{0.95} & $0.00,0.00$ & $-0.08,0.21$ & $-0.24,0.68$ & $-0.40,1.25$ & $-0.49,1.58$ \\
& $0.33,0.67$ & $0.28,0.81$ & $0.17,1.12$ & $0.06,1.50$ & $0.01,1.72$ \\
\hline \multirow{2}{*}{1.00} & $0.33,0.67$ & $0.28,0.77$ & $0.17,0.97$ & $0.06,1.18$ & $0.01,1.30$ \\
\hline & $0.00,0.00$ & $-0.08,0.08$ & $-0.24,0.24$ & $-0.40,0.40$ & $-0.49,0.49$ \\
& $0.33,0.67$ & $0.28,0.72$ & $0.17,0.83$ & $0.06,0.94$ & $0.01,0.99$ \\
\hline
\end{tabular}

The model is $n_{t}=\eta_{n k} k_{t}+\eta_{n a} a_{t}, y_{t}=\eta_{y k} k_{t}+\eta_{y a} a_{t}$.

This table reports $\eta_{n k}, \eta_{n a}$ above $\eta_{y k}, \eta_{y a}$. 
Table 4

Consumption and Capital Elasticities for the Nonseparable Variable-Labor Model with Technology Shocks

\begin{tabular}{|c|c|c|c|c|c|}
\hline \multirow[b]{2}{*}{$\phi=$} & \multicolumn{5}{|c|}{$\sigma=$} \\
\hline & 0 & 0.2 & 1 & 5 & $\infty$ \\
\hline \multirow[t]{2}{*}{0.00} & $0.23,0.35$ & $0.37,0.28$ & $0.54,0.07$ & $0.71,-0.30$ & $0.82,-0.62$ \\
\hline & $1.00,0.08$ & & $0.94,0.13$ & $0.91, \quad 0.20$ & $0.89, \quad 0.26$ \\
\hline \multirow{2}{*}{0.50} & $0.23,0.35$ & $0.37,0.29$ & $0.54,0.10$ & $0.71,-0.24$ & $0.82,-0.53$ \\
\hline & $1.00,0.08$ & $0.97,0.09$ & $0.94,0.13$ & $0.91, \quad 0.19$ & $0.89, \quad 0.24$ \\
\hline \multirow{2}{*}{0.95} & $0.23,0.42$ & $0.37,0.42$ & $0.54,0.29$ & $0.71, \quad 0.09$ & $0.82,-0.06$ \\
\hline & $1.00,0.07$ & $0.97,0.07$ & $0.94,0.09$ & $0.91, \quad 0.45$ & $0.89, \quad 0.16$ \\
\hline \multirow{2}{*}{1.00} & $0.23,0.77$ & $0.37,0.63$ & $0.54,0.46$ & $0.71, \quad 0.29$ & $0.82, \quad 0.18$ \\
\hline & $1.00,0.00$ & $0.97,0.03$ & $0.94,0.06$ & $0.91, \quad 0.09$ & $0.89, \quad 0.11$ \\
\hline
\end{tabular}

The model is $c_{t}=\eta_{c k} k_{t}+\eta_{c a} a_{t}, k_{t+1}=\eta_{k k} k_{t}+\eta_{k a} a_{t}$.

This table reports $\eta_{c k}, \eta_{c a}$ above $\eta_{k k}, \eta_{k a}$.

Table 5

Employment and Output Elasticities for the Nonseparable Variable-Labor Model with Technology Shocks

\begin{tabular}{|c|c|c|c|c|c|}
\hline \multirow[b]{2}{*}{$\phi=$} & \multicolumn{5}{|c|}{$\sigma$} \\
\hline & 0 & 0.2 & 1 & 5 & $\infty$ \\
\hline 0.00 & $\begin{array}{ll}0.13, & 0.38 \\
0.42, & 0.92\end{array}$ & $\begin{array}{r}-0.05,0.46 \\
0.30,0.98\end{array}$ & $\begin{array}{r}-0.24,0.71 \\
0.17,1.14\end{array}$ & $\begin{array}{r}-0.45,1.16 \\
0.03,1.44\end{array}$ & $\begin{array}{ll}-0.58, & 1.54 \\
-0.05, & 1.69\end{array}$ \\
\hline 0.50 & $\begin{array}{ll}0.13, & 0.38 \\
0.42, & 0.92 \\
\end{array}$ & $\begin{array}{rr}-0.05, & 0.45 \\
0.30, & 0.97\end{array}$ & $\begin{array}{rr}-0.24, & 0.68 \\
0.17, & 1.12\end{array}$ & $\begin{array}{r}-0.45,1.09 \\
0.03,1.40\end{array}$ & $\begin{array}{ll}-0.58, & 1.44 \\
-0.05, & 1.63\end{array}$ \\
\hline 0.95 & $\begin{array}{ll}0.13, & 0.30 \\
0.42, & 0.87\end{array}$ & $\begin{array}{r}-0.05,0.29 \\
0.28,0.86\end{array}$ & $\begin{array}{rr}-0.24, & 0.45 \\
0.17, & 0.97\end{array}$ & 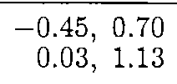 & $\begin{array}{ll}-0.58, & 0.88 \\
-0.05, & 1.25\end{array}$ \\
\hline 1.00 & $\begin{array}{l}0.13,-0.13 \\
0.42,0.58\end{array}$ & $\begin{array}{r}-0.05,0.05 \\
0.30,0.70\end{array}$ & $\begin{array}{rr}-0.24, & 0.24 \\
0.17, & 0.83\end{array}$ & $\begin{array}{rr}-0.45, & 0.45 \\
0.03, & 0.97\end{array}$ & $\begin{array}{ll}-0.58, & 0.58 \\
-0.05, & 1.05\end{array}$ \\
\hline
\end{tabular}

The model is $n_{t}=\eta_{n k} k_{t}+\eta_{n a} a_{t}, y_{t}=\eta_{y k} k_{t}+\eta_{y a} a_{t}$.

This table reports $\eta_{n k}, \eta_{n a}$ above $\eta_{y k}, \eta_{y a}$. 
Table 6

Consumption and Capital Elasticities for the Separable Variable-Labor Model with Government Consumption Shochs

\begin{tabular}{c|c|c|c|c|c|}
\multicolumn{7}{c}{$\phi=$} & $0,0.00$ & $0.2,0.35$ & $1,1.20$ & $5,2.31$ & $\infty, 3.00$ \\
\hline \multirow{2}{*}{0.00} & $0.70,-0.02$ & $0.66,-0.02$ & $0.60,-0.01$ & $0.55,-0.01$ & $0.53,-0.01$ \\
& $0.96,-0.02$ & $0.96,-0.02$ & $0.95,-0.02$ & $0.93,-0.02$ & $0.93,-0.02$ \\
\hline \multirow{2}{*}{0.50} & $0.70,-0.03$ & $0.66,-0.03$ & $0.60,-0.03$ & $0.55,-0.02$ & $0.53,-0.02$ \\
& $0.96,-0.02$ & $0.96,-0.02$ & $0.95,-0.02$ & $0.93-0.02$ & $0.93,-0.02$ \\
\hline \multirow{2}{*}{0.95} & $0.70,-0.18$ & $0.66,-0.16$ & $0.60,-0.12$ & $0.55,-0.10$ & $0.53,-0.09$ \\
& $0.96,-0.01$ & $0.96,-0.01$ & $0.95,-0.00$ & $0.93,0.00$ & $0.93,0.00$ \\
\hline \multirow{2}{*}{1.00} & $0.70,-0.36$ & $0.66,-0.30$ & $0.60,-0.21$ & $0.55,-0.16$ & $0.53,-0.14$ \\
& $0.96,-0.00$ & $0.96,-0.00$ & $0.95,0.01$ & $0.93,0.02$ & $0.93,0.02$ \\
\hline
\end{tabular}

The model is $c_{t}=\eta_{c k} k_{t}+\eta_{c x} x_{t}, k_{t+1}=\eta_{k k} k_{t}+\eta_{k x} x_{t}$.

This table reports $\eta_{c k}, \eta_{c x}$ above $\eta_{k k}, \eta_{k x}$.

\section{Table 7}

Employment and Output Elasticities for the Separable Variable-Labor Model with Government Consumption Shocks

\begin{tabular}{c|c|r|r|r|c|}
\multicolumn{1}{c}{$\phi=$} & $0,0.00$ & \multicolumn{1}{c}{$\sigma_{n}, \nu\left(\sigma_{n}\right)=$} \\
\hline \multirow{2}{*}{0.00} & $0.00,0.00$ & $-0.11,0.01$ & $-0.31,0.02$ & $-0.51,0.03$ & $-0.60,0.04$ \\
& $0.33,0.00$ & $0.26,0.00$ & $0.12,0.01$ & $-0.01,0.02$ & $-0.07,0.02$ \\
\hline \multirow{2}{*}{0.50} & $0.00,0.00$ & $-0.11,0.01$ & $-0.31,0.03$ & $-0.51,0.05$ & $-0.60,0.06$ \\
& $0.33,0.00$ & $0.26,0.01$ & $0.12,0.02$ & $-0.01,0.04$ & $-0.07,0.04$ \\
\hline \multirow{2}{*}{0.95} & $0.00,0.00$ & $-0.11,0.05$ & $-0.31,0.15$ & $-0.51,0.23$ & $-0.60,0.27$ \\
& $0.33,0.00$ & $0.26,0.04$ & $0.12,0.10$ & $-0.01,0.16$ & $-0.07,0.18$ \\
\hline \multirow{2}{*}{1.00} & $0.00,0.00$ & $-0.11,0.11$ & $-0.31,0.26$ & $-0.51,0.38$ & $-0.60,0.43$ \\
& $0.33,0.00$ & $0.26,0.07$ & $0.12,0.17$ & $-0.01,0.25$ & $-0.07,0.29$ \\
\hline
\end{tabular}

The model is $n_{t}=\eta_{n k} k_{t}+\eta_{n x} x_{t}, y_{t}=\eta_{y k} k_{t}+\eta_{y x} x_{t}$.

This table reports $\eta_{n k}, \eta_{n x}$ above $\eta_{y k}, \eta_{y 2}$. 


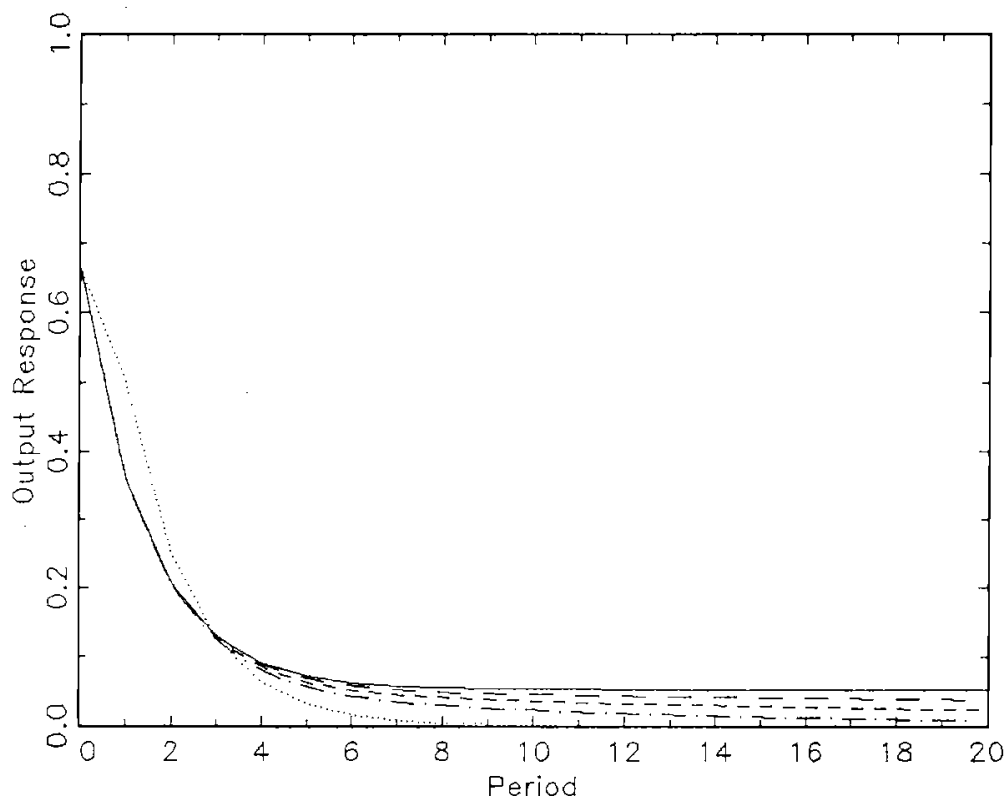

Figure 1a: Output Response to a Technology Shock With Fixed Labor Supply and $\phi=0.5$

The solid line gives the percentage response of output to a $1 \%$ technology shock in a model with fixed labor supply when the intertemporal elasticity of substitution $\sigma=0$. The long dashed line gives the response when $\sigma=0.2$. The short dashed line gives the response when $\sigma=1$. The dashed and dotted line gives the response when $\sigma=5$. The dotted line gives the response when $\sigma=\infty$. In all cases the initial response is $\alpha=0.667$. 


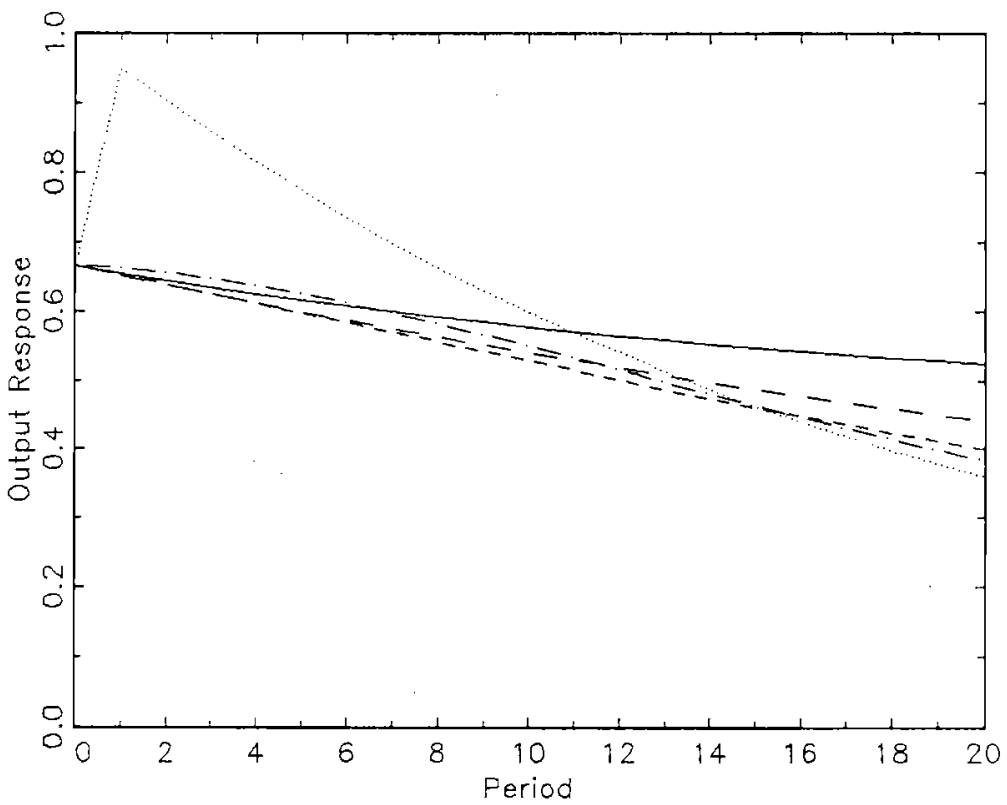

Figure 1b: Output Response to a Techmology Shock With Fixed Labor Supply and $\phi=0.95$

The solid line gives the percentage response of output to a $1 \%$ technology shock in a nodel witl fixed labor supply when the intertemporal elasticity of substitution $\sigma=0$. The long dashed line gives the response when $\sigma=0.2$. The short dashed line gives the response when $\sigma=1$. The dashed and dotted line gives the response when $\sigma=5$. The dotted line gives the response when $\sigma=\infty$. In all cases the initial response is $\alpha=0.667$. 


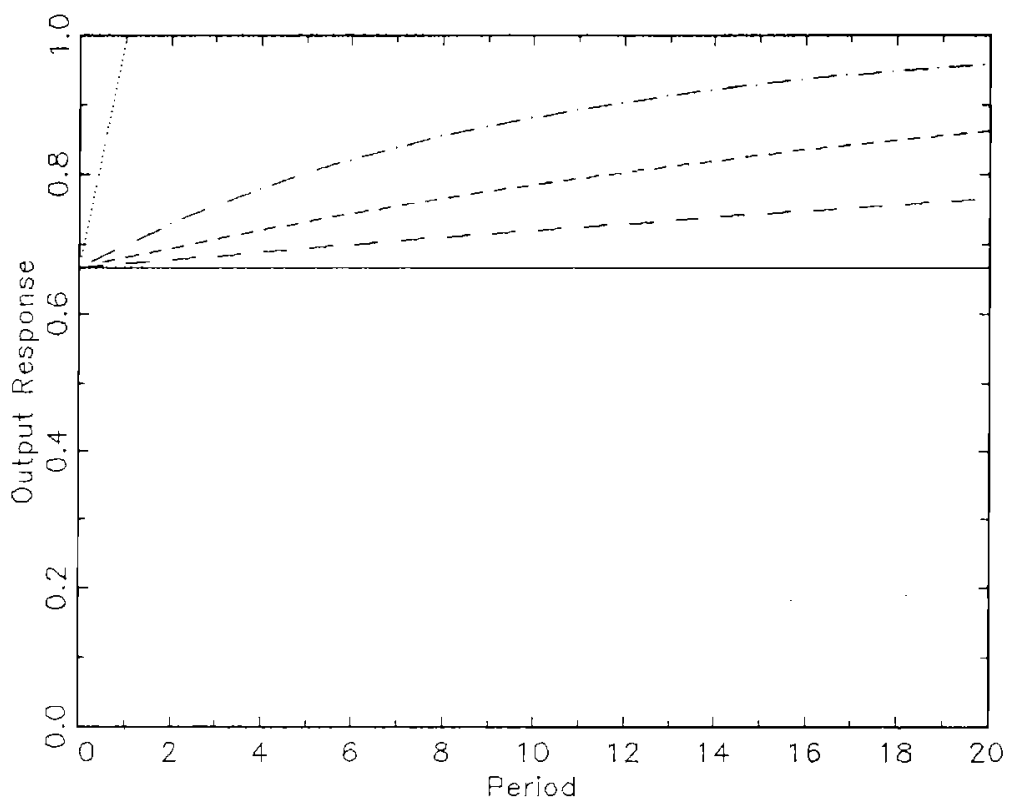

Figure 1c: Output Response to a Technology Shock With Fixed Labor Supply and $\phi=1$

The solid line gives the percentage response of output to a $1 \%$ technology shock in a model with fixed labor supply when the intertemporal elasticity of substitution $\sigma=0$. The long dashed line gives the response when $\sigma=0.2$. The short dashed line gives the response when $\sigma=1$. The dashed and dotted line gives the response when $\sigma=5$. The dotted line gives the response when $\sigma=\infty$. In all cases the initial response is $\alpha=0.667$. 


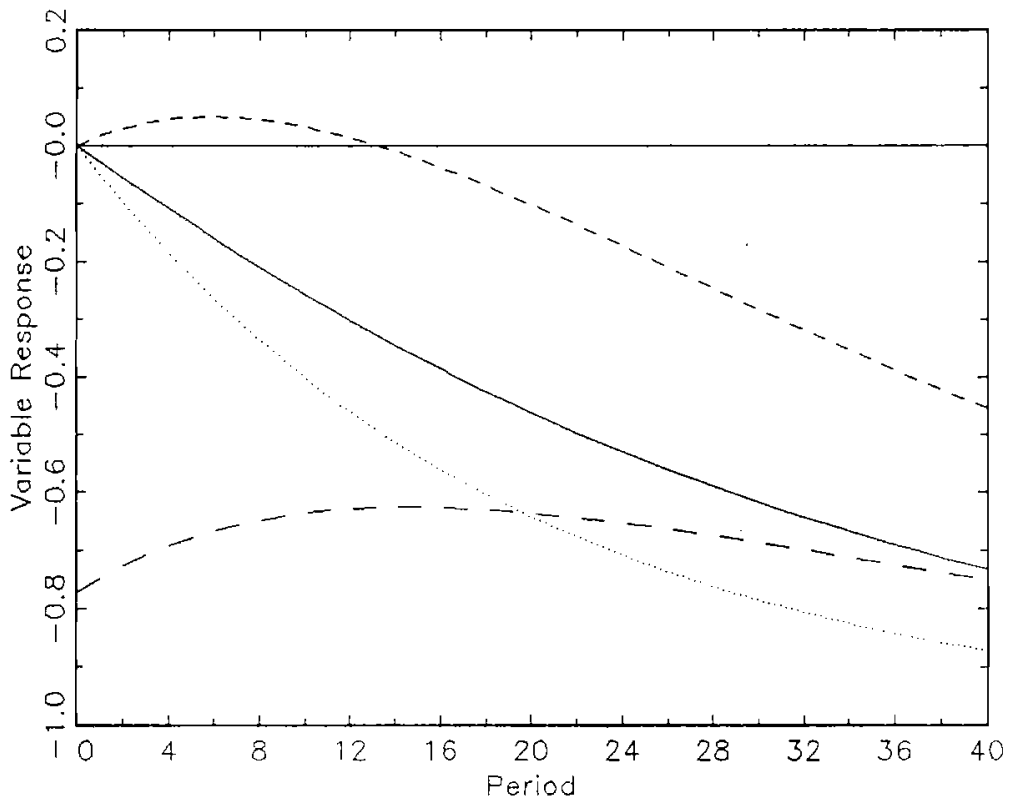

Figure 2: Response of the Economy to a Productivity Slowdown With Fixed Labor Supply

This figure shows the percentage responses of several variables to a $1 \%$ permanent negative decline in technology, accompanied by a $1 \%$ transitory increase in technology with persistence $\phi=0.95$. The dotted line gives the implied path of technology. The responses of other variables are calculated in a model witl. fixed labor supply and intertemporal elasticity of substitution $\sigma$ equal to one. The long dashed line gives the response of consumption, the short dashed line gives the response of the capital stock, and the solid line gives the response of output. 


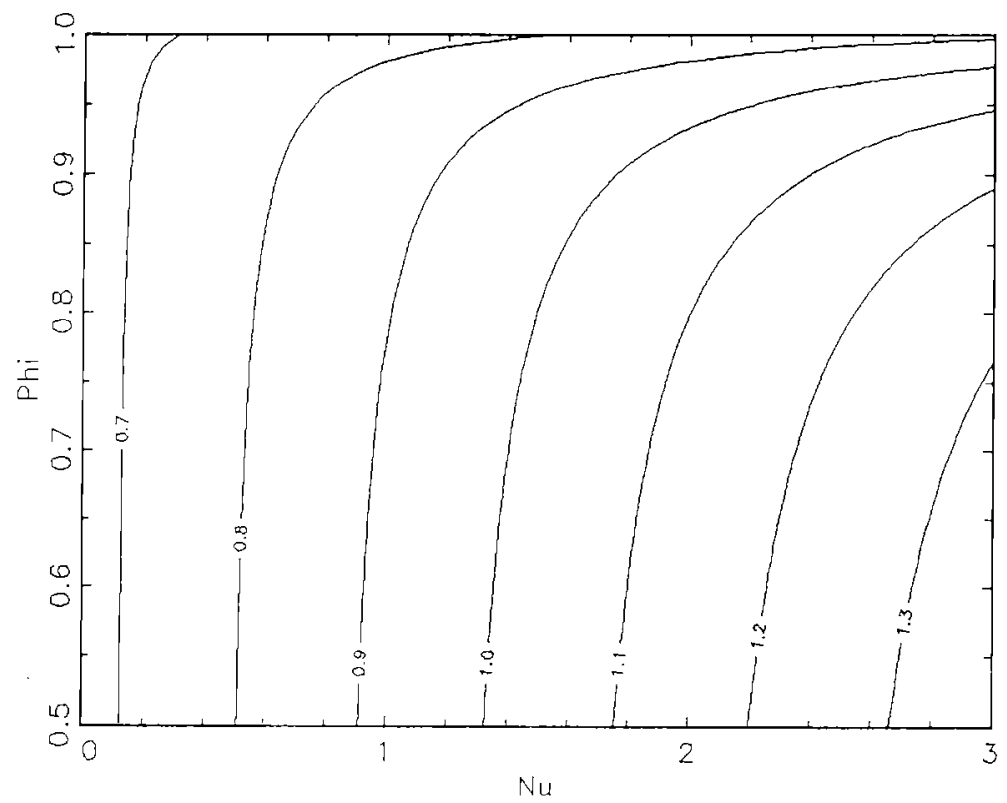

\section{Figure 3: Initial Output Response to a Technology Shock With Variable Labor Supply and Separable Utility}

The contours show the elasticity of output with respect to technology in a model with variable labor supply and additively separable utility over consumption and leisure. The model is specified in equations (3.1)-(3.9) in the text. The elasticity is plotted for diferent values of the parameters $\nu$ and $\phi$, where $\nu$ is a function of the elasticity of labor supply defined in equation (3.9), and $\phi$ is the persistence of technology shocks. 'The contour lines are 0.1 apart. Note that the smallest value of $\phi$ shown is 0.5 , and that when $\nu=0$ the elasticity is $\alpha=0.667$ for any value of $\phi$. 


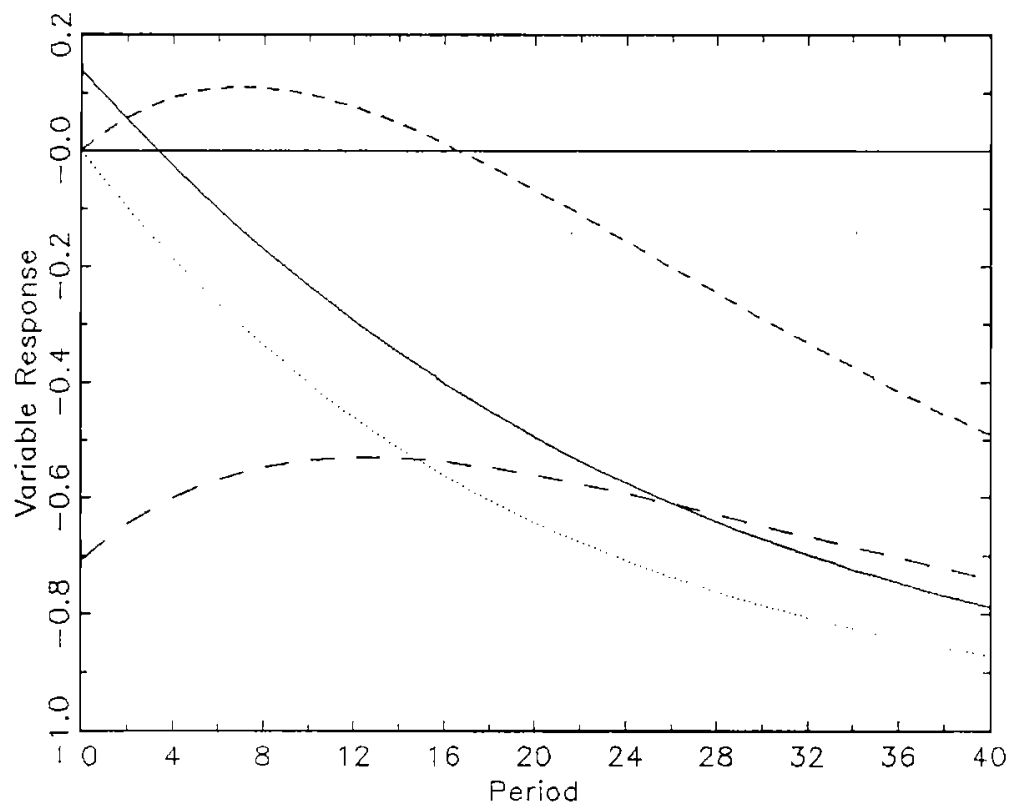

Figure 4: Response of the Economy to a Productivity Slowdown With Variable Labor Supply and Separable Utility

This figure shows the percentage responses of several variables to a $1 \%$ permanent negative decline in technology, accompanied by a $1 \%$ transitory increase in technology with persistence $\phi=0.95$. The dotted line gives the implied path of technology. The responses of other variables are calculated in a model with variable labor supply and additively separable utility over consumption and leisure. The model is specified in equations (3.1)-(3.9) in the text. The elasticity of labor supply $\sigma_{n}$ is assumed to equal one. The long dashed line gives the response of consumption, the short dashed line gives the response of the capital stock, and the solid line gives the response of output. 


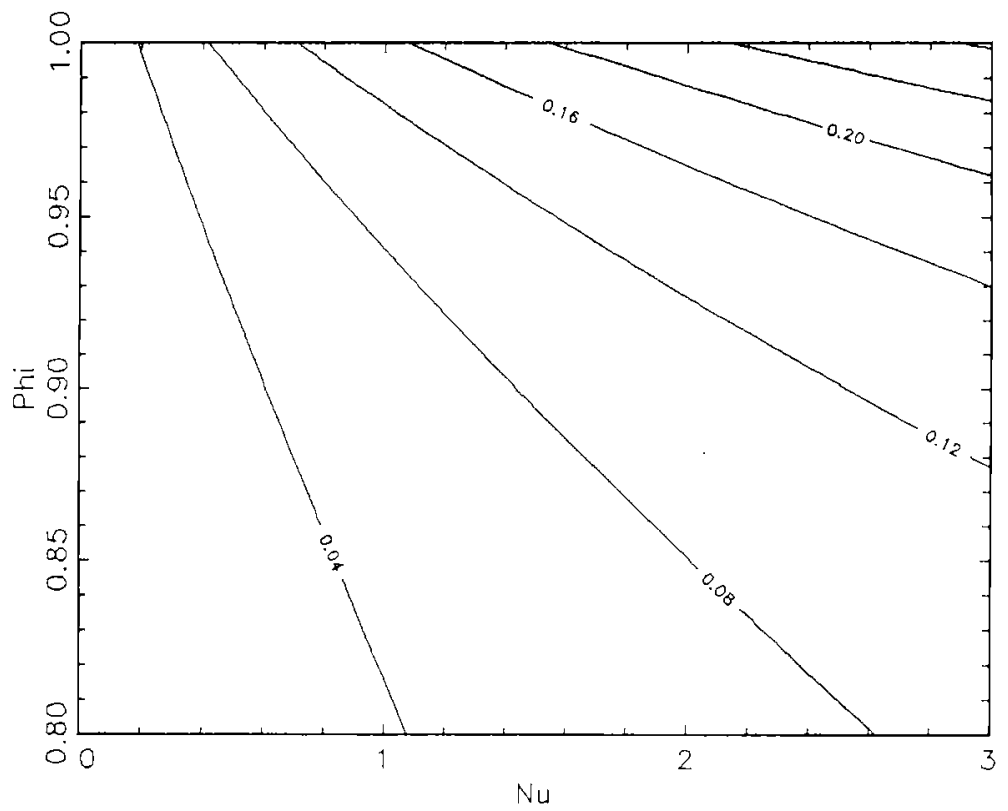

\section{Figure 5: Initial Output Response to a Government Consumption Shock With Variable Labor Supply and Separable Utility}

The contours show the elasticity of output with respect to government consumption in a model with variable labor supply and additively separable utility over consumption and leisure. The model is specified in equations (4.1)-(4.6) in the text. The elasticity is plotted for different values of the parameters $\nu$ and $\phi$, where $\nu$ is a function of the elasticity of labor supply defined in equation (3.9), and $\phi$ is the persistence of government consumption shocks. The contour lines are 0.04 apart. Note that the smallest value of $\phi$ shown is 0.8 , and that when $\nu=0$ the elasticity is zero for any value of $\phi$. 